\title{
Heme scavenging reduces pulmonary endoplasmic reticulum stress, fibrosis, and emphysema
}

\author{
Saurabh Aggarwal, ${ }^{1,2}$ Israr Ahmad, ${ }^{1}$ Adam Lam, ${ }^{1,2}$ Matthew A. Carlisle, ${ }^{1,2}$ Changzhao Li, ${ }^{3}$ \\ J. Michael Wells, ${ }^{4,5,6,7}$ S. Vamsee Raju, ${ }^{4,5,6}$ Mohammad Athar, ${ }^{3}$ Steven M. Rowe, ${ }^{4,5,6}$ \\ Mark T. Dransfield, ${ }^{4,5,6,7}$ and Sadis Matalon ${ }^{1,2}$ \\ 'Department of Anesthesiology and Perioperative Medicine, Division of Molecular and Translational Biomedicine, \\ ${ }^{2}$ Pulmonary Injury and Repair Center, ${ }^{3}$ Department of Dermatology, ${ }^{4}$ Department of Medicine, Division of Pulmonary, \\ Allergy and Critical Care Medicine, ${ }^{5} \mathrm{UAB}$ Lung Health Center, and ${ }^{6} \mathrm{Gregory}$ Fleming James Cystic Fibrosis Research \\ Center, School of Medicine, University of Alabama at Birmingham, Birmingham, Alabama, USA. 'Birmingham Veterans \\ Administration Medical Center, Birmingham, Alabama, USA.
}

Pulmonary fibrosis and emphysema are irreversible chronic events after inhalation injury. However, the mechanism(s) involved in their development remain poorly understood. Higher levels of plasma and lung heme have been recorded in acute lung injury associated with several insults. Here, we provide the molecular basis for heme-induced chronic lung injury. We found elevated plasma heme in chronic obstructive pulmonary disease (COPD) (GOLD stage 4) patients and also in a ferret model of COPD secondary to chronic cigarette smoke inhalation. Next, we developed a rodent model of chronic lung injury, where we exposed C57BL/6 mice to the halogen gas, bromine $\left(\mathrm{Br}_{2}\right)(400 \mathrm{ppm}, 30$ minutes), and returned them to room air resulting in combined airway fibrosis and emphysematous phenotype, as indicated by high collagen deposition in the peribronchial spaces, increased lung hydroxyproline concentrations, and alveolar septal damage. These mice also had elevated pulmonary endoplasmic reticulum (ER) stress as seen in COPD patients; the pharmacological or genetic diminution of ER stress in mice attenuated $\mathrm{Br}_{2}$-induced lung changes. Finally, treating mice with the heme-scavenging protein, hemopexin, reduced plasma heme, ER stress, airway fibrosis, and emphysema. This is the first study to our knowledge to report elevated heme in COPD patients and establishes heme scavenging as a potential therapy after inhalation injury.

Authorship note: SA and IA contributed equally to this work.

Conflict of interest: The authors have declared that no conflict of interest exists.

License: Copyright 2018, American Society for Clinical Investigation.

Submitted: March 12, 2018 Accepted: September 13, 2018 Published: November 2, 2018

\section{Reference information:} JCI Insight. 2018;3(21):e120694. https://doi.org/10.1172/jci. insight.120694.

\section{Introduction}

Inhaled toxic gases (such as high levels of oxygen, cigarette smoke, and halogens) may cause injury to various levels of the mammalian respiratory tract, resulting in mild to severe disease. Although acute inhalation injury may subside in a few days, the long-term complications may be devastating. In this study, we demonstrated the development of combined airway fibrosis and pulmonary emphysema-like pathologies after inhalation injury in C57BL/6 mice exposed to the halogen gas bromine $\left(\mathrm{Br}_{2}\right)$ for 30 minutes. Interestingly, there is a growing recognition of coexistence of both emphysema and lung fibrosis in patients with chronic lung injury (1-8). The majority of these patients have a history of either acute toxic gas inhalation or prolonged cigarette smoking, and present with very severe chronic obstructive pulmonary disease (COPD) with clinical and imaging features of both lung fibrosis and emphysema $(4,9,10)$. Cigarette smoke-induced COPD characterized by increased collagen deposition around bronchioles and emphysema have also been reported in mice and ferrets (11-14). In our rodent model, alveolar septal damage and airspace enlargement after a brief exposure to $\mathrm{Br}_{2}$ far exceeds those obtained in mice exposed to cigarette smoke for 2 to 6 months $(15,16)$.

People exposed to $\mathrm{Br}_{2}$ during transportation accidents or acts of terrorism often develop acute lung injury and respiratory failure (17-20). $\mathrm{Br}_{2}$ is commonly used in industrial applications including water disinfection, and as bleach, flame retardant, insecticide, drilling fluid, and gasoline additive. $\mathrm{Br}_{2}$ along with $\mathrm{Cl}_{2}$ are important toxic constituents of tobacco smoke (21). $\mathrm{Br}_{2}$ and its hydrolysis product, hypobromous acid, react with plasmalogens to form longer-living intermediates (brominated aldehydes and fatty acids), 
capable of transducing injury to distal sites (22). We previously showed that $\mathrm{Br}_{2}$ gas damaged red blood cells (RBCs) and increased plasma and lung levels of free heme in mice (23). RBCs are especially susceptible to oxidative damage, and we and others have shown that lipid peroxidation of RBC membranes increases their osmotic fragility $(23,24)$, resulting in the release of hemoglobin $(\mathrm{Hb})$ and free heme $(25)$.

Nonencapsulated heme is an important injurious agent in several pathologies such as the endothelial injury after lipopolysaccharide exposure (26), lung injury after Libby amphibole asbestos exposure (27), hyperoxia-induced lung injury (28), pulmonary hypertension in sickle cell anemia (29), and trauma-hemorrhage (30). Nonencapsulated heme causes oxidative stress by generating reactive species and redox-active iron capable of initiating lipid peroxidation $(31,32)$. It intercalates into cell membranes and causes oxidative loss of plasma membrane integrity (33). Heme is also capable of producing peroxynitrite by Fenton chemistry using $\mathrm{NO}_{2}^{-}$and $\mathrm{H}_{2} \mathrm{O}_{2}$, which are stable end-products of nitric oxide and superoxide degradation (34). Physiologically, blood heme concentrations are maintained at low levels (35) by the high binding affinity of serum albumin, hemopexin ( $\mathrm{Hx})$, and haptoglobin (36-39). Hx is a plasma protein with the highest binding affinity for free heme $\left(K_{d}\right.$ near $\left.10^{-13} \mathrm{M}\right)$. Since heme is a reactive, lipophilic molecule of limited water solubility, Hx maintains heme in a soluble, monomeric state in aqueous environments. After heme binding, the heme-Hx complex is transported to liver and internalized by macrophages through receptor-mediated endocytosis (40).

The endoplasmic reticulum (ER) is an important target of heme-mediated reactive species, which induce ER stress (41). ER stress and the unfolded protein response (UPR) constitute a homeostatic response to accumulation of misfolded proteins. When unfolded or misfolded proteins accumulate in the ER lumen, the first response is to attenuate further protein translation, which reduces the ER load and prevents accumulation of unfolded proteins. Although the UPR serves a protective role that allows cells to deal with noxious stimuli, prolonged ER stress contributes to the development and progression of several pathologies, including pulmonary fibrosis (42) and emphysema (43).

In this study, we demonstrated the presence of elevated plasma heme levels and ER stress in COPD patients, in ferrets exposed to cigarette smoke, and in mice 14 to 21 days after a brief exposure to $\mathrm{Br}_{2}$ gas (400 ppm for 30 minutes). Furthermore, we showed that elevated plasma heme levels after $\mathrm{Br}_{2}$ exposure in mice may be responsible for ER stress and associated lung pathologies that resemble human pulmonary fibrosis and pulmonary emphysema (airway enlargement and increased lung compliance). Heme scavenging by $\mathrm{Hx}$, administered at 1 hour or 5 days after $\mathrm{Br}_{2}$ exposure, ameliorated ER stress, attenuated fibrotic and emphysematous changes, and improved survival. Thus, we have developed a model of pulmonary emphysema-like injury, which mimics and exceeds the lung pathology following long-term exposure to cigarette smoke, provided a plausible mechanism for the development of pulmonary emphysema, and showed that the pathology and mortality may be mitigated by $\mathrm{Hx}$ administered long after the inhaled insult.

\section{Results}

Plasma heme and ER stress is elevated in patients with severe COPD and in a ferret model of COPD. Earlier studies have shown that plasma heme levels are increased in several insults such as sepsis, hyperoxia, and trauma, which may ultimately lead to lung injury $(26-30,44)$. However, the effects of heme on the development of chronic lung airway and distal lung pathologies are not known. We measured plasma heme in patients that never smoked and in individuals with COPD (Figure 1A). Demographic and clinical data for these patients is shown in Table 1. Heme levels were significantly elevated in very severe COPD patients (Global Initiative for Chronic Obstructive Lung Diseases, GOLD stage 4) (45) compared to never-smokers and to those with mild-to-moderate COPD (GOLD stages 2 and 3) (Figure 1B). Next, we demonstrated that ferrets that were exposed to 60 minutes of smoke from 3R $4 \mathrm{~F}$ research cigarettes, twice daily for 6 months, also had elevated heme levels in the plasma (Figure 1C). We have previously shown that these ferrets develop morphological and functional lung changes similar to COPD, including emphysematous alveolar enlargement and reduced lung function (14). Prolonged ER stress and the activation of the adaptive UPR have been implicated in the development of chronic lung injury $(42,46,47)$. We found that patients with COPD (GOLD stage 4) had significantly elevated levels of Grp78/Bip (Figure 1D), a master regulator of the UPR (48).

Rodent model of airway fibrosis and emphysema after inhalation injury. To investigate our human findings that elevated heme levels may be involved in chronic lung damage, we developed a rodent model of inhalation injury. We found that C57BL/6 mice of either sex exposed to $400 \mathrm{ppm}$ of $\mathrm{Br}_{2}$ gas for 30 minutes and returned to room air had elevated plasma heme levels for up to 14 days after exposure (Figure 2A). 
A

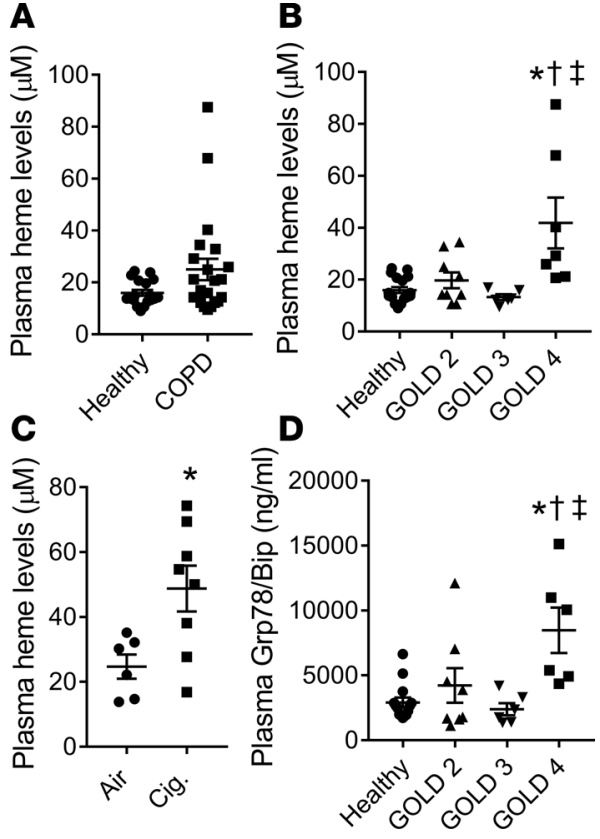

Figure 1. Plasma heme and ER stress levels are elevated in patients with very severe COPD and in ferrets exposed to cigarette smoke. Total heme levels were measured in the plasma of COPD patients and their healthy counterparts. Although total heme levels were not significantly higher in COPD patients compared with the healthy individuals $(P=$ 0.06) $(n=18-22)(\mathbf{A})$, the stratification of patients according to the severity of the disease revealed significantly elevated plasma heme in COPD patients with GOLD stage 4 disease compared with the healthy individuals or patients with the mild disease $(n=6-18)$ (B). Plasma heme levels were also significantly higher in ferrets exposed to cigarette smoke for 6 months, which induced emphysema and attenuated lung function ( $n=6-8)$ (C). ELISA showed that GOLD stage 4 COPD patients had significantly higher levels of ER stress marker Grp78/Bip $(n=6-14)$ (D). Values are means \pm SEM. ${ }^{*} P<0.05$ versus healthy patients or air-exposed ferrets; ${ }^{\dagger} P<0.05$ versus COPD GOLD stage $2 ;{ }^{\ddagger} P<0.05$ versus COPD GOLD stage 3 , by unpaired $t$ test for 2 groups or 1-way ANOVA followed by Tukey's post hoc testing for more than 2 groups.

To determine if elevated heme correlated with chronic lung injury, we measured lung injury markers on days $1,7,14$, and 21 after $\mathrm{Br}_{2}$ exposure. Our data demonstrated that $\mathrm{Br}_{2}$ increased bronchoalveolar lavage fluid (BALF) protein levels (Figure 2B) and total cell count (Figure 2C) on days 14 and 21 after exposure. After staining the lungs for $\alpha$-smooth muscle actin ( $\alpha$-SMA) (Figure 2D) or with Masson's trichrome stain (Figure 2E), we found increased thickening of the smooth muscle layer around bronchioles and marked accumulation of collagen in the lungs, primarily around bronchioles on days 14 and 21 after exposure. The histological observation of lung airway fibrotic changes was accompanied by a significant increase in lung parenchymal hydroxyproline levels on days 14 and 21 after exposure (Figure 2F).

Next, measurements of pressure-volume (PV) relationships in anesthetized mice with flexiVent at 7 to 21 days after exposure demonstrated that $\mathrm{Br}_{2}$ exposure resulted in increased lung volumes, lung compliance, and inspiratory capacity, starting at 14 days after exposure (Figure 3A and Supplemental Figure 1, A and B; supplemental material available online with this article; https://doi.org/10.1172/jci.insight.120694DS1). Subsequently, we stained the lungs with hematoxylin and eosin (H\&E) (Figure 3B) and measured the alveolar mean linear intercept $\left(\mathrm{L}_{\mathrm{m}}\right.$ ) (Figure 3C). $\mathrm{L}_{\mathrm{m}}$ was increased in mice on days 14 and 21 after $\mathrm{Br}_{2}$ gas inhalation. These pathological changes in the lung function and structure are characteristic of alveolar wall

Table 1. Demographic and clinical data of COPD patients

\begin{tabular}{|c|c|c|c|c|}
\hline & Total $(n=40)$ & Non-COPD $(n=18)$ & $\operatorname{COPD}(n=22)$ & $P$ value \\
\hline Age in years & $59 \pm 9$ & $56 \pm 12$ & $61 \pm 7$ & 0.13 \\
\hline White race & $17(43 \%)$ & $6(33 \%)$ & $11(50 \%)$ & 0.06 \\
\hline Male sex & $18(45 \%)$ & $5(28 \%)$ & $13(59 \%)$ & 0.35 \\
\hline FEV1 (liters) & $1.85 \pm 0.80$ & $2.37 \pm 0.82$ & $1.42 \pm 0.45$ & $<0.001$ \\
\hline FEV1, percentage predicted & $67 \pm 21$ & $86 \pm 12$ & $52 \pm 13$ & $<0.001$ \\
\hline FVC (liters) & $2.96 \pm 0.90$ & $3.02 \pm 0.95$ & $2.91 \pm 0.88$ & 0.90 \\
\hline Current smoker & $18(45 \%)$ & $10(56 \%)$ & $8(36 \%)$ & 0.34 \\
\hline Smoking history, pack-year ${ }^{A}$ & $29 \pm 25$ & $13 \pm 18$ & $43 \pm 23$ & $<0.001$ \\
\hline
\end{tabular}

FEV1, postbronchodilator forced expiratory volume in 1 second; FVC, postbronchodilator forced vital capacity. ${ }^{A}$ Pack-year = (number of cigarettes smoked per day)/(20 x number of years of cigarette smoking). Data expressed as mean \pm SD, or $n$ (\%). Mann-Whitney $U$ test or Fisher's exact test were used to measure differences between means and proportions, respectively. 
A

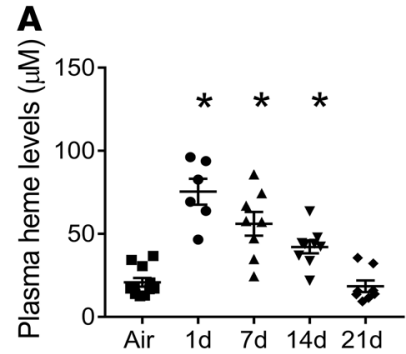

D
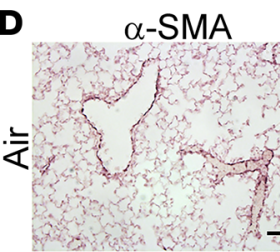

$\alpha-S M A$

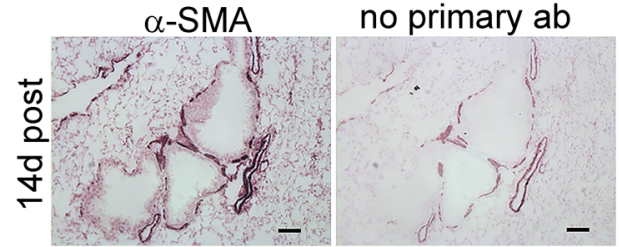

E

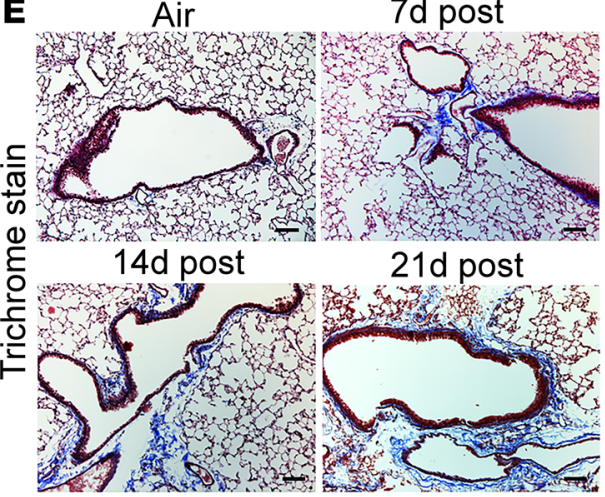

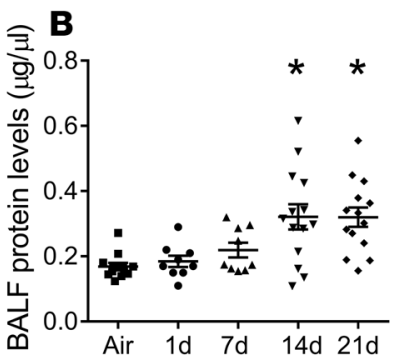

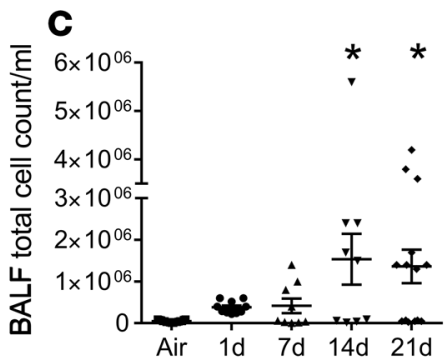

$\alpha-S M A$

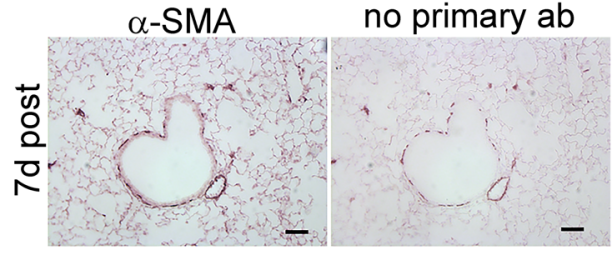

$\alpha-S M A$

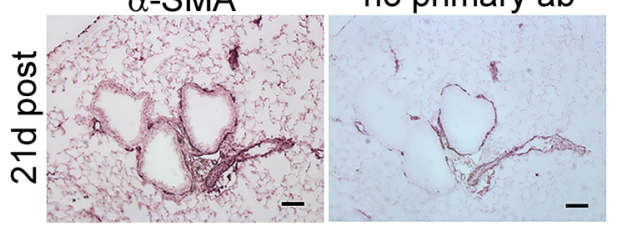

$\mathbf{F}$

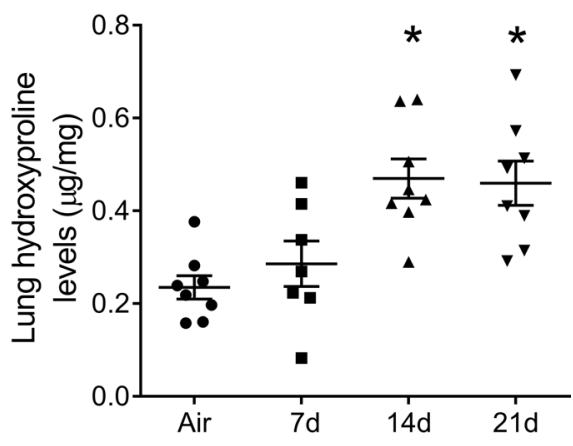

Figure 2. Lung injury and fibrosis in rodent model of inhalation injury. Male C57BL/6 mice were exposed to air or $\mathrm{Br}$, gas (400 ppm, 30 minutes) and returned to room air. Plasma heme and acute and chronic lung injury parameters were measured in mice on days 1, 7, 14, or 21 after $\mathrm{Br}_{2}$ exposure. Plasma levels of total heme were elevated in mice until 14 days after $\mathrm{Br}_{2}$ inhalation ( $\left.n=6-11\right)(\mathbf{A})$. Bronchoalveolar lavage fluid (BALF) showed a significant increase in protein levels $(n=9-14)$ (B) and total cell count $(n=9-17)$ (C) on days 14 and 21 after $\mathrm{Br}_{2}$ inhalation. Peripheral lung tissue staining for $\alpha$-smooth muscle actin $(\alpha$-SMA) $(n=5)$ (D) and with Masson's trichrome stain $(n=5)(\mathbf{E})$ demonstrated an increased accumulation of $\alpha$-SMA and thickening of the smooth muscle layer and collagen deposition (blue stain) primarily around airways on days 14 and 21 after $\mathrm{Br}_{2}$. Characteristic images were obtained from the indicated number of lungs for each condition. Similarly, the quantification of collagen by measuring lung hydroxyproline levels showed significant increases at 14 and 21 days after $\mathrm{Br}_{2}$ inhalation (F). Values are means \pm SEM. ${ }^{*} P<0.05$ versus air-exposed C57BL/6 mice by 1-way ANOVA followed by Tukey's post hoc test. Scale bars are $100 \mu \mathrm{m}$.

destruction and airspace enlargement seen in both experimental models of emphysema and in patients. The release of proteinases such as elastase by macrophages and neutrophils plays a significant role in alveolar wall destruction (49). Plasma elastase levels (Figure 3D) and BALF elastase activity (Figure 3E) were increased in mice on days 14 and 21 after $\mathrm{Br}_{2}$ exposure.

ER stress is elevated in mice exposed to $\mathrm{Br}_{2}$ gas. We immunoblotted peripheral lung tissue of mice exposed to $\mathrm{Br}_{2}$ and returned to room air, with antibodies against Grp78/Bip (Figure 4A) and the downstream 3 major branches (protein markers) of the UPR: the double-stranded RNA-activated protein kinase-like ER kinase (p-PERK) (phosphorylated active form) (Figure 4B), the inositol-requiring enzyme 1 (p-IRE1) (active form) (Figure 4C), and the activating transcription factor 6 (ATF6) (Figure 4D). GRP78/Bip and p-PERK levels were elevated in lungs of mice at days 14 and 21 after $\mathrm{Br}_{2}$ exposure, while p-IRE1 and ATF6 were not. The activation of PERK 

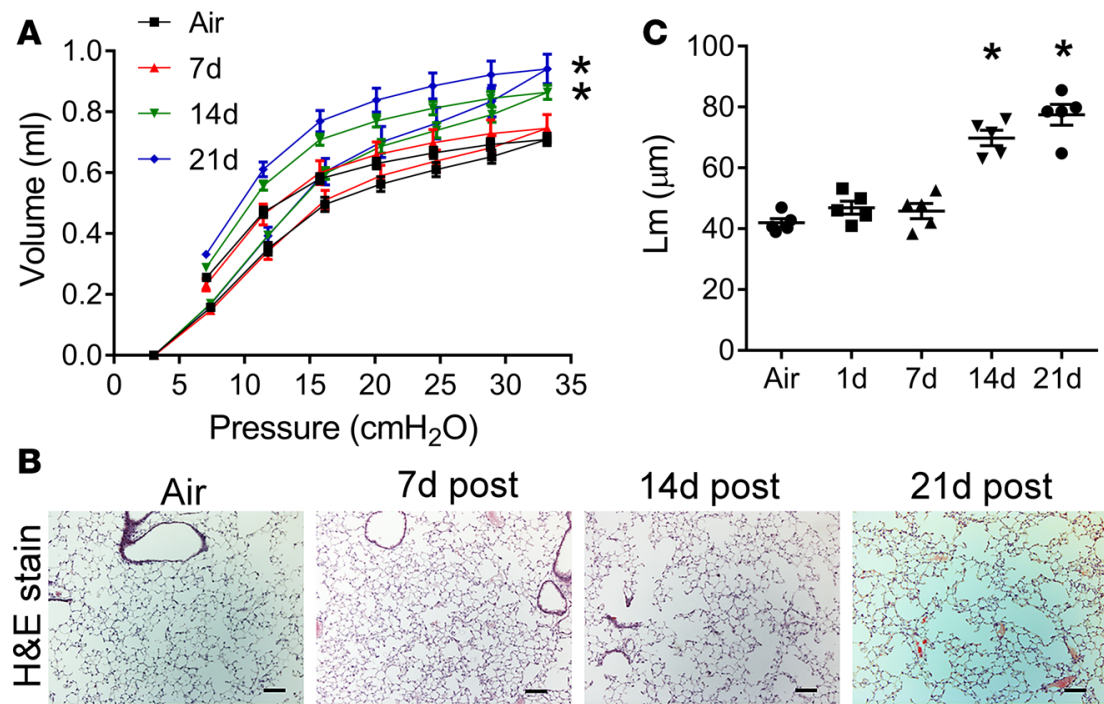

$7 \mathrm{~d}$ post

14d post

21d post
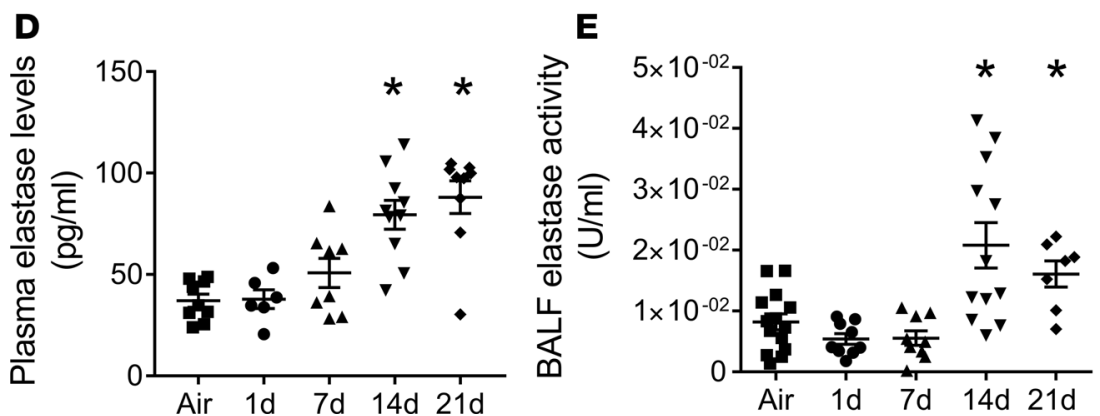

Figure 3. Acute exposure to $\mathrm{Br}_{2}$ induces lung emphysematous changes. Male $\mathrm{C} 57 \mathrm{BL} / 6$ mice were exposed to air or $\mathrm{Br}_{2}$ gas (400 ppm, 30 minutes) and then returned to room air. On days 7, 14, or 21 after $\mathrm{Br}_{2}$ exposure, mouse lung compliance was assessed by the slope of the deflation limbs of pressure-volume (PV) curves. $\mathrm{Br}_{2}$ inhalation increased lung volumes as indicated by shifting up and left of PV curves on days 14 and 21 after exposure $(n=5-9)(\mathbf{A})$. The staining of peripheral lung tissue with hematoxylin and eosin (H\&E) showed airspace enlargement (B) and increased alveolar mean linear intercept $\left(\mathrm{L}_{m}\right)(n=5)$. Scale bars are $100 \mu \mathrm{m}$. (C) on days 14 and 21 after exposure. Characteristic images are shown. Finally, plasma elastase levels $(n=6-10)$ (D) and BALF elastase activity $(n=7-14)$ (E) were elevated in $\mathrm{Br}_{2}$-exposed mice on days 14 and 21 after exposure. Values are means \pm SEM. ${ }^{*} P<0.05$ versus air-exposed C57BL/6 mice by 1-way ANOVA followed by Tukey's post hoc test. PV curves were analyzed by 2-way ANOVA with Bonferroni's post hoc test.

leads to global inhibition of protein translation, with the exception of select proteins such as activating transcription factor 4 (ATF4) and the CCAAT/enhancer-binding protein homologous protein (CHOP). Both ATF4 (Figure $4 \mathrm{E}$ ) and $\mathrm{CHOP}$ (Figure $4 \mathrm{~F}$ ) protein levels were elevated in the lungs of mice on day 14 after $\mathrm{Br}_{2}$ inhalation.

ER stress induces airway fibrosis and distal lung injury resembling human emphysema. To confirm the role of ER stress and the UPR in the pathogenesis of fibrosis and emphysema, we treated mice daily with a single i.p. injection of the ER stress inhibitor salubrinal ( $1 \mathrm{mg} / \mathrm{kg} \mathrm{BW}$ ), starting at 1 hour after $\mathrm{Br}_{2}$ exposure until day 13 , and analyzed changes in lung histology and function on the 14th day after exposure. Salubrinal is a selective inhibitor of eukaryotic initiation factor $2 \alpha(\mathrm{eIF} 2 \alpha)$ dephosphorylation and has been shown to protect against ER stress-mediated apoptosis $(50,51)$. eIF2 $\alpha$ must be dephosphorylated to enable the translation of new proteins. Salubrinal attenuates unfolded or misfolded protein synthesis by inhibiting eIF $2 \alpha$ dephosphorylation, thus decreasing $\mathrm{CHOP}$ and rescuing cells from apoptosis (52). We found a significant increase in lung phosphorylated eIF2 $\alpha$ (active form) (Figure 5A) and a corresponding decrease in CHOP (Figure 5B) levels in mice treated with salubrinal after $\mathrm{Br}_{2}$ exposure. Furthermore, salubrinal ameliorated BALF protein levels (Figure 5C) and BALF total cell count (Figure 5D). Masson's trichrome staining of lungs (Figure 5E) and quantification of lung hydroxyproline levels (Figure $5 \mathrm{~F}$ ) showed decreased collagen levels and lung fibrotic changes in $\mathrm{Br}_{2}$-exposed mice after treatment with salubrinal. Additionally, $\mathrm{PV}$ curve measurements demonstrated that salubrinal prevented $\mathrm{Br}_{2}$-induced increase in lung volumes (Figure 6A), as well as lung compliance and inspiratory capacity (Supplemental Figure 2, A and B). Salubrinal also attenuated alveolar $\mathrm{L}_{\mathrm{m}}$ (Figure 6C), as shown 
A
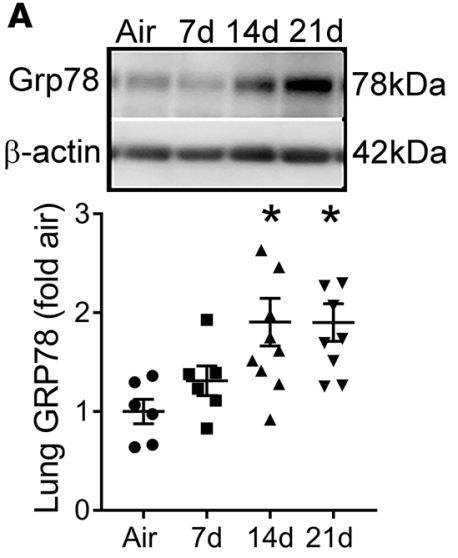

D
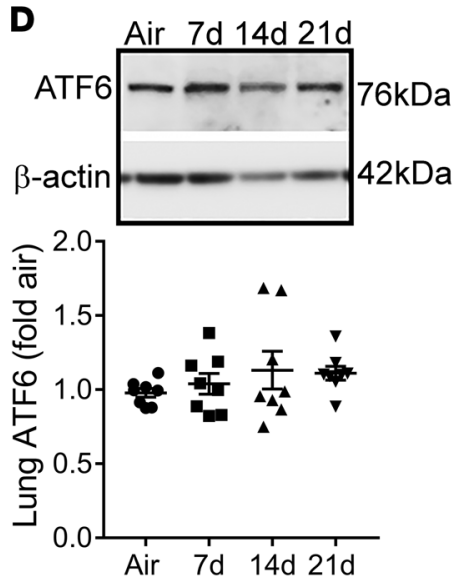
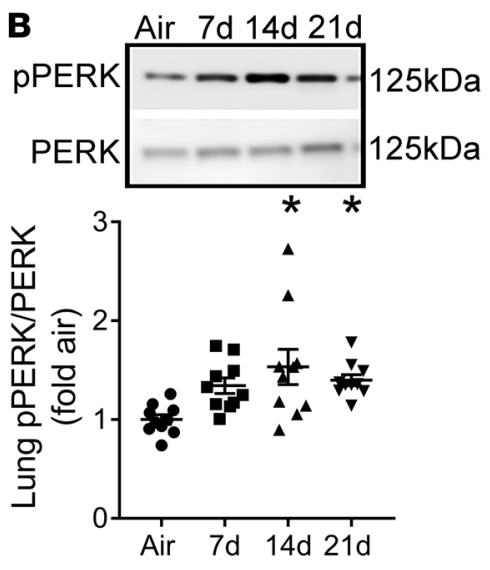

E
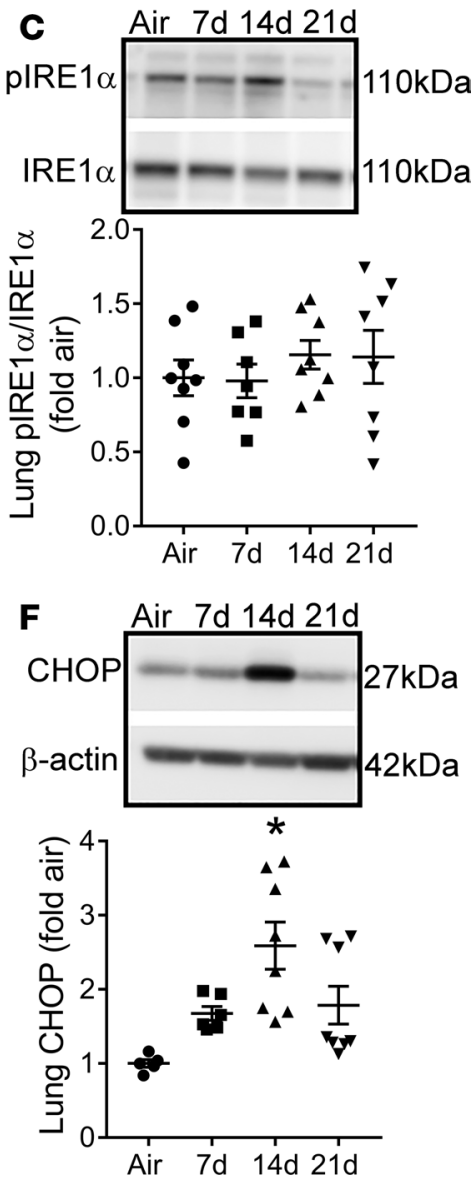

Figure 4. ER stress is increased in $\mathbf{B r}_{2}$-exposed mice. Male $C 57 \mathrm{BL} / 6$ mice were exposed to air or $\mathrm{Br}_{2}$ gas (400 ppm, 30 minutes) and then returned to room air. On days 7, 14, or 21 after exposure, lungs were harvested and immunoblotted for ER stress markers Grp78/Bip ( $n=6-10)(\mathbf{A})$, phospho-PERK ( $n=10)(\mathbf{B})$, phospho-IRE1 $\alpha(n=8)(\mathbf{C})$, and ATF6 $(n=8)(\mathbf{D})$. Br exposure increased the lung expression of Grp78, phopho-PERK and the downstream transcriptional effectors of the PERK pathway ATF4 $(n=7)(\mathbf{E})$ and CHOP $(n=5-8)(\mathbf{F}), 14$ days after exposure. Values are means \pm SEM. ${ }^{*} P<0.05$ versus air-exposed [57BL/6 mice by 1-way ANOVA followed by Tukey's post hoc test.

on H\&E staining (Figure 6B), plasma elastase levels (Figure 6D), and BALF elastase activity (Figure 6E) in comparison with the mice treated with DMSO after $\mathrm{Br}_{2}$ exposure.

All 3 branches of the UPR regulate the activation of CHOP, a central mediator of ER stress-induced apoptosis and pulmonary fibrosis (42); however, ATF4 is considered to be a major inducer of CHOP expression. Therefore, we subjected ATF4-haplodeficient mice (ATF4 ${ }^{+-}$) to $\mathrm{Br}_{2}$ (400 ppm, 30 minutes) and investigated whether these mice are protected against $\mathrm{Br}_{2}$-induced lung pathology 14 days after exposure. ATF4-homodeficient mice $\left(\mathrm{ATF}^{-/-}\right.$) had severe developmental abnormalities and were not used in these experiments. Our results demonstrated that $\mathrm{ATF}^{+/-}$mice had lower lung levels of ATF4 (Figure 7A) and CHOP (Figure 7B) after $\mathrm{Br}_{2}$ inhalation compared with the corresponding wild-type (WT) mice. Exposure to $\mathrm{Br}_{2}$ increased lung collagen deposition (trichrome staining) (Figure 7C) and lung hydroxyproline levels (Figure 7D) in the WT mice, but not in the ATF4 $4^{+/-}$mice. In addition, $\mathrm{ATF} 4^{+/-}$mice did not develop an emphysematous phenotype after $\mathrm{Br}_{2}$ inhalation, as demonstrated by the lack of changes in PV curves (Figure 7E) and the demonstrable no increase in lung compliance and inspiratory capacity (Supplemental Figure 3, A and B). In addition, $\mathrm{ATF}^{+/-}$mice did not have an increase in $\mathrm{L}_{\mathrm{m}}$ (Figure $7 \mathrm{~F}$ ) on $\mathrm{H} \& \mathrm{E}$ staining (Figure 7C), plasma elastase levels (Figure 7G), and BALF elastase activity (Figure $7 \mathrm{H}$ ) after $\mathrm{Br}_{2}$ exposure. In comparison, WT mice showed emphysematous lung changes. Together, these results suggest that prolonged ER stress impairs lung injury repair, which leads to the development of lung fibrotic and emphysematous changes.

Heme scavenging attenuates ER stress and prevents the development of chronic lung injury. First, to investigate if heme may lead to ER stress, we incubated human bronchial epithelial cells (HBECs) with hemin (a form of heme, $25 \mu \mathrm{M}$ ), and saw increased ER stress markers ATF4 and CHOP (Figure 8A) within 6 hours after hemin 

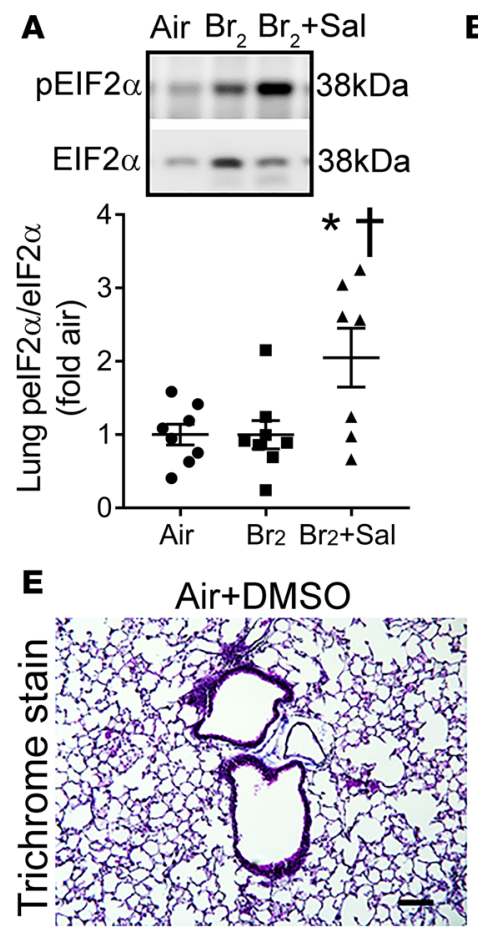

c
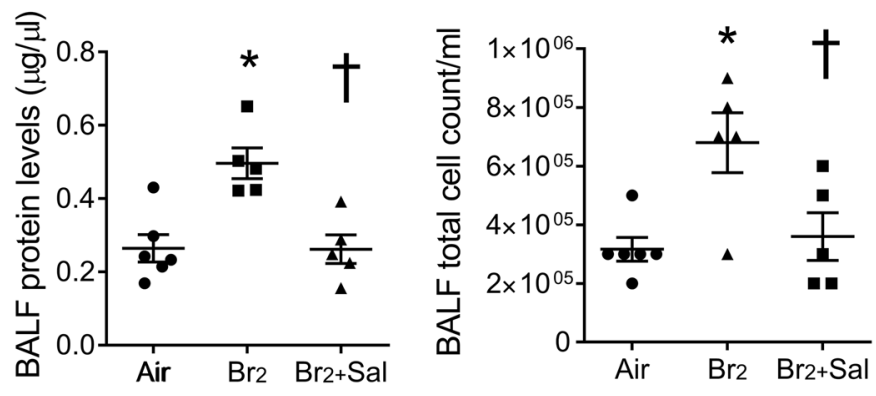

Figure 5. Attenuation of ER stress abrogates lung injury and fibrosis. Male C57BL/6 mice were exposed to air or $\mathrm{Br}$, gas (400 ppm, 30 minutes) and then returned to room air. Some $\mathrm{Br}_{2}$-exposed mice received an intraperitoneal injection of the ER stress inhibitor salubrinal (1 mg/kg BW), starting at 1 hour after $\mathrm{Br}_{2}$ exposure, and then daily for 13 consecutive days. Air-exposed and some $\mathrm{Br}_{2}$-exposed mice received DMSO (vehicle) as a control. Fourteen days after $\mathrm{Br}_{2}$ exposure, immunoblot of lung tissue showed that salubrinal increased phospho-elF2 $\alpha$ levels ( $\left.n=7-8\right)(\mathbf{A})$ but decreased lung CHOP levels $(n=12-13)(B)$ after $\mathrm{Br}_{2}$ exposure. Salubrinal also attenuated BALF protein $(n=5-6)(\mathbf{C})$ and total cell count ( $\left.n=5-6\right)(\mathbf{D})$ in Br -exposed mice. Masson's trichrome staining $(n=5)(\mathbf{E})$ and quantification of lung hydroxyproline levels $(n=5-6)$. Scale bars are $100 \mu$ m. (F) showed a decrease in collagen levels and lung fibrotic changes 14 days after $\mathrm{Br}_{2}$ exposure in salubrinal-treated mice. Values are means \pm SEM. ${ }^{*} P<0.05$ versus air + DMSO-treated mice and ${ }^{\dagger} P<$ 0.05 versus $\mathrm{Br}_{2}+$ DMSO-treated mice by 1-way ANOVA followed by Tukey's post hoc test.

challenge. In contrast, exposure of these cells to $\mathrm{Br}_{2}$ (100 ppm, 10 minutes) (in the absence of exogenous heme) only increased ATF4, while CHOP levels remained unaltered (Supplemental Figure 4). Next, to determine if heme scavenging can abrogate ER stress, we gave an i.p. injection of the heme-scavenging protein $\mathrm{Hx}$ (purified human plasma $\mathrm{Hx}, 4 \mu \mathrm{g} / \mathrm{g} \mathrm{BW}$ ) to mice, 1 hour after $\mathrm{Br}_{2}$ exposure. Plasma concentrations of human $\mathrm{Hx}$ in the plasma of mice up to 24 hours after a single injection of $\mathrm{Hx}$ are shown in Supplemental Figure 5A. $\mathrm{Hx}$ administration reduced plasma heme after $\mathrm{Br}_{2}$ exposure (Figure $8 \mathrm{~B}$ ). Hx reduced ER stress as indicated by low levels ATF4 (Figure 8C) and CHOP (Figure 8D) in the lungs 14 days after $\mathrm{Br}_{2}$ exposure. Similarly, immunohistochemical staining of lung sections showed that ATF4 and CHOP (Figure 8E) levels were higher and predominantly expressed around bronchioles 14 days after $\mathrm{Br}_{2}$ exposure. Treatment with $\mathrm{Hx}$ attenuated ATF4 and CHOP levels around airways and completely abrogated the ER stress markers in the lung parenchyma.

To ascertain the therapeutic potential of $\mathrm{Hx}$ in preventing or reversing chronic lung damage after inhalation injury, we gave an i.p. injection of purified human $\mathrm{Hx}(4 \mu \mathrm{g} / \mathrm{g} \mathrm{BW})$ to mice, either 1 hour after $\mathrm{Br}_{2}$ exposure, or in some key experiments 5 days after $\mathrm{Br}_{2}$. Our results indicate that the plasma concentration of mouse $\mathrm{Hx}$ was significantly higher in mice that were administered purified human $\mathrm{Hx} 1$ hour after $\mathrm{Br}_{2}$ exposure on day 14 after exposure (Supplemental Figure 5, B and C). Hx administered either at 1 hour or 5 days after $\mathrm{Br}_{2}$ significantly reduced BALF protein levels (Figure 9A), BALF total cell count (Figure 9B), lung collagen levels on Masson's trichrome staining (Figure 9C), and lung hydroxyproline levels (Figure 9D) in mice 14 days after $\mathrm{Br}_{2}$ inhalation. $\mathrm{Hx}$ also reduced alveolar $\mathrm{L}_{\mathrm{m}}$ (Figure 9E) upon H\&E staining (Figure 9C), prevented the shifting of the PV curve (Figure 9F), and an increase in lung compliance and inspiratory capacity (Supplemental Figure 6, A and B). Hx-treated mice also had lower plasma elastase levels (Figure 9G) and BALF elastase activity (Figure 9H) 14 days after $\mathrm{Br}_{2}$ gas inhalation. Finally, postexposure injection with $\mathrm{Hx}$ reduced overall mortality in C57BL/6 mice compared with mice injected with saline after $\mathrm{Br}_{2}$ inhalation (Figure 9I). 

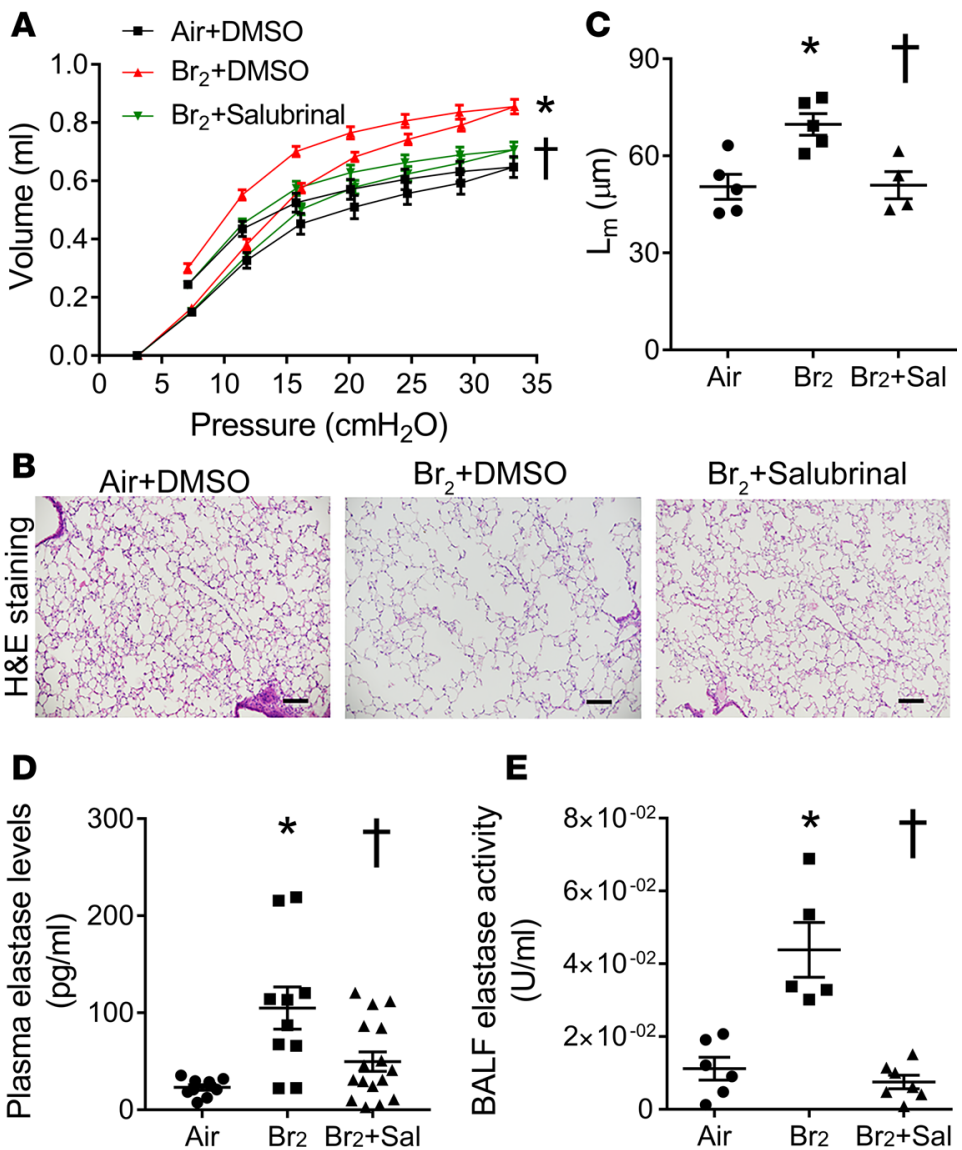

Figure 6. Attenuation of ER stress reduces lung emphysematous changes. Male C57BL/6 mice were exposed to air or $\mathrm{Br}_{2}$ gas (400 ppm, 30 minutes) and then returned to room air. Some $\mathrm{Br}_{2}$-exposed mice were given an intraperitoneal injection of the ER stress inhibitor salubrinal $(1 \mathrm{mg} / \mathrm{kg} \mathrm{BW})$, starting at 1 hour after $\mathrm{Br}_{2}$ exposure, and then daily for 13 consecutive days. Air-exposed and some $\mathrm{Br}_{2}$-exposed mice received DMSO (vehicle) as a control. Fourteen days after $\mathrm{Br}_{2}$ exposure, the lung volumes were increased in mice as indicated by the shifting up and left of the pressure-volume (PV) curves. ( $n=5-6)(A)$. Staining of peripheral lung tissue with hematoxylin and eosin (H\&E) showed airspace enlargement $(n=5)(B)$, which was quantified by measuring alveolar mean linear intercept $\left(L_{m}\right)$ $(n=5)$. Scale bars $100 \mu \mathrm{m}$. (C). Treatment with salubrinal attenuated these $\mathrm{Br}_{2}$-induced emphysematous changes in mouse lung. Salubrinal also reduced plasma elastase levels $(n=10-16)$ (D) and BALF elastase activity $(n=5-7)(E)$ in $\mathrm{Br}_{2}$-exposed mice. Values are means \pm SEM. All animals were males. ${ }^{*} P<0.05$ versus air + DMSO-treated mice and ${ }^{2} P<0.05$ versus $\mathrm{Br}_{2}+$ DMSO-treated mice by 1-way ANOVA followed by Tukey's post hoc test. PV curves were analyzed by 2-way ANOVA with Bonferroni's post hoc test.

\section{Discussion}

This is the first study to our knowledge to report that patients with very severe COPD have elevated levels of plasma heme and the ER stress marker Grp78/Bip. In addition, our rodent model of inhalation injury shows that heme-induced ER stress is involved in aberrant airway remodeling and alveolar septal damage, leading to the development of airway fibrosis and pulmonary emphysema. Finally, our data suggest that heme scavenging after acute inhalation injury may reduce ER stress and prevent chronic lung damage.

Inhalation lung injury caused by irritant gases such as $\mathrm{Br}_{2}, \mathrm{Cl}_{2}, \mathrm{NH}_{3}$, and $\mathrm{COCl}_{2}$ is a major source of morbidity and mortality during environmental or accidental disasters. These inhaled substances may affect the respiratory system at various levels and generate reactive intermediates that reach the systemic circulation, thus causing multi-organ injury (53-56). Individuals and animals exposed to these toxic gases may develop noncardiogenic pulmonary edema and also significant myocardial injury within hours to days of exposure $(23,55)$. Those that survive often suffer from residual chronic lung disease, with airflow obstruction, fibrosis, airway hyper-reactivity, and impaired gas exchange (57-60). In our study, the histological examination of mouse lungs after halogen exposure showed evidence of airway fibrosis, alveolar 

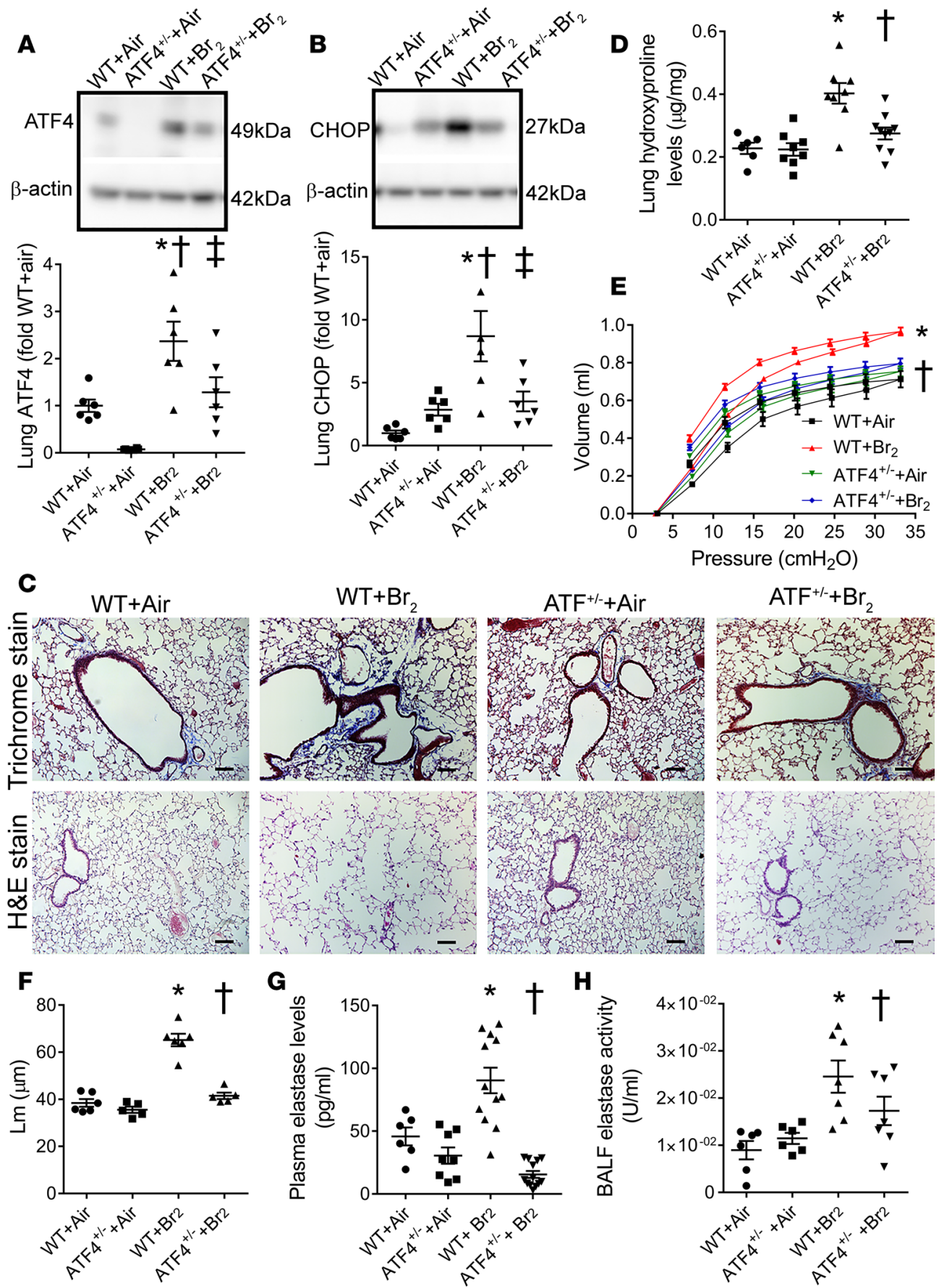

Figure 7. ATF4-haplodeficient mice $\left(\mathrm{ATF}^{+/-}\right)$mice are protected against inhalation injury. Male wild-type (WT, C57BL/6) and ATF4+/- mice were exposed to air or $\mathrm{Br}_{2}$ gas $(400 \mathrm{ppm}, 30$ minutes) and then returned to room air. Fourteen days later, mouse lungs were harvested. Immunoblot analyses showed that ATF4 ${ }^{+/-}$mice had lower lung ATF4 $(n=6)(\mathbf{A})$ and CHOP levels $(n=6)(B)$ compared with WT mice exposed to $\mathrm{Br}_{2}$. Masson's trichrome staining $(n=5)(C)$ and quantification of lung hydroxyproline levels ( $n$ = 6-10). Scale bars are $100 \mu \mathrm{m}$. (D) showed increased collagen deposition primarily around airways in the WT mice compared with the ATF4 ${ }^{+/-}$mice. Assessment of lung pressure-volume (PV) curves demonstrated that $\mathrm{Br}_{2}$ exposure increased lung volumes as indicated by shifting up and left of PV curve in the WT but not the ATF4 ${ }^{+/-}$ mice ( $n=4$ for $W T+$ air and $n=5$ for others) (E). Staining of peripheral lung tissue with hematoxylin and eosin (H\&E) showed airspace enlargement after $\mathrm{Br}_{2}$ exposure $(n=5-6)$ in WT but not $\mathrm{ATF}^{+/-}$mice (C), which was quantified by measuring alveolar mean linear intercept $\left(L_{m}\right)(n=5-6)(\mathbf{F})$. Plasma elastase levels $(n=6-13)(\mathbf{G})$ and BALF elastase activity $(n=6-7)$ (H) were significantly higher in the WT compared with the ATF4 ${ }^{+/-}$mice after $\mathrm{Br}_{2}$ exposure. Values are means \pm SEM. ${ }^{*} P<0.05$ versus $\mathrm{WT}+$ air, ${ }^{\dagger} P$ $<0.05$ versus $\mathrm{ATF}^{+/-}+$air, and $\ddagger P<$ 0.05 versus $W T+\mathrm{Br}_{2}$ for $\mathbf{A}$ and $\mathbf{B}$; ${ }^{\dagger} P<$ 0.05 versus $W T+\mathrm{Br}_{2}$ for $\mathbf{D}-\mathbf{H}$ by 1 -way ANOVA followed by Tukey's post hoc test. PV curves were analyzed by 2-way ANOVA with Bonferroni's post hoc test.

septal damage, and enlarged alveolar air spaces. No animal model mimics human COPD exactly. However, the pattern of lung injury in our mice after $\mathrm{Br}_{2}$ exposure approximates some of the features (such as increased lung compliance, alveolar enlargement, higher elastase levels) seen in patients with a long history of smoking who present with combined airway fibrosis and emphysema (3, 6, 61-64). It is highly interesting that the increase in lung compliance and airspace enlargement after a brief exposure to $\mathrm{Br}_{2}$ far exceeds those obtained in mice exposed to cigarette smoke for 2 to 6 months $(15,16)$, suggesting that our inhalation-injury rodent model may be a reasonable animal model to study COPD pathogenesis and also to test countermeasures.

ER stress and the UPR have been associated with development of fibrotic remodeling in lungs and other organs (65-68). Specifically, an increase in lung CHOP levels has been shown to mediate lung fibrosis, while the genetic deficiency or pharmacological inhibition of $\mathrm{CHOP}$ by tauroursodeoxycholic acid 

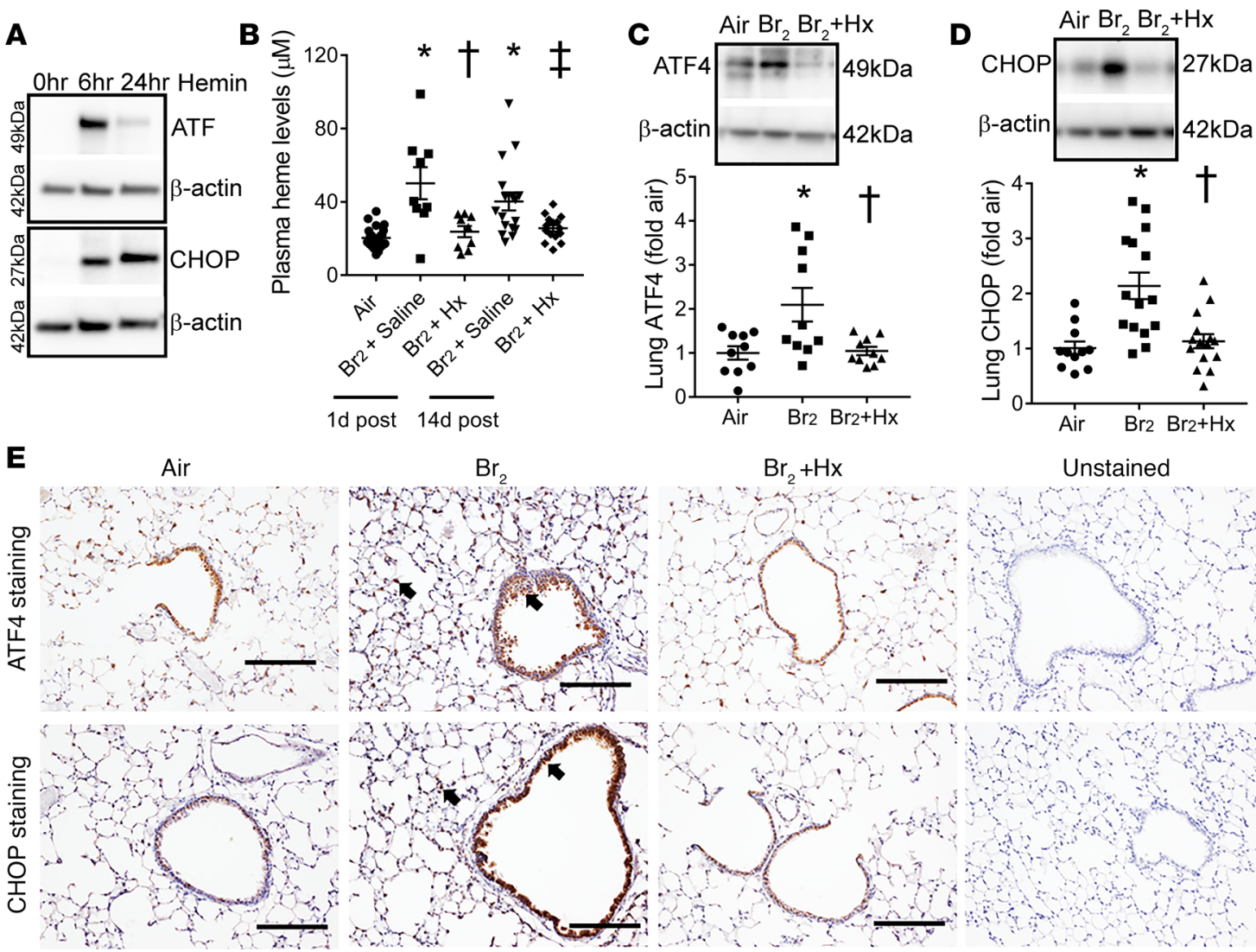

Unstained

Figure 8. Heme scavenging attenuates ER stress. Immunoblot analysis showed that the incubation of the human bronchial epithelial cells with hemin (a form of heme, $25 \mu \mathrm{M}$ ), increased the ER stress markers ATF4 and CHOP $(n=3)(A)$ at 6 and 24 hours after hemin challenge. In addition, male C57BL/6 mice were exposed to air or $\mathrm{Br}_{2}$ gas (400 ppm, 30 minutes) and then returned to room air. Some $\mathrm{Br}_{2}$-exposed mice were given an intraperitoneal injection of purified human hemopexin $(\mathrm{Hx})(4 \mu \mathrm{g} / \mathrm{g} \mathrm{BW}) 1$ hour after $\mathrm{Br}_{2}$ exposure. All air-exposed mice and some $\mathrm{Br}_{2}$-exposed mice received saline injection as an appropriate control. $\mathrm{Hx}$ attenuated plasma total heme levels in $\mathrm{Br}_{2}$-exposed mice $(n=9-24)(\mathbf{B})$. Immunoblotting showed that $\mathrm{Hx}$ lowered $\mathrm{Br}_{2}$-induced ER stress markers, ATF4 $(n=10)(\mathbf{C})$ and CHOP $(n=11-15)(\mathbf{D})$, in mouse lungs 14 days after $\mathrm{Br}_{2}$ exposure. Similarly, immunohistochemical staining of lung sections showed an increased accumulation of ATF4 and CHOP $(n=4-5)$ (E) (arrows showing brown stain) lining bronchioles and in the lung parenchyma in $\mathrm{Br}_{2}$-exposed mice 14 days after exposure. Hx lowered ATF4 and CHOP levels. Values are mean \pm SEM. All animals were males. Scale bars are $200 \mu$ m. For A, ${ }^{*} P<0.05$ versus air + saline, ${ }^{\dagger} P<0.05$ versus $\mathrm{Br}_{2}+$ saline (1 day after), and ${ }^{\ddagger} P<0.05$ versus $\mathrm{Br}_{2}+$ saline (14 days after); for $\mathbf{B}$ and $\mathbf{C},{ }^{\dagger} P<0.05$ versus $\mathrm{Br}_{2}+$ saline (14 days after) by 1-way ANOVA followed by Tukey's post hoc test.

(TUDCA) attenuated the bleomycin-induced pulmonary fibrosis and inflammation $(69,70)$. We previously showed that mice exposed to chlorine have elevated UPR marker p-PERK in their skin and lungs at 1 and 6 hours after exposure (71). In our current study, we found that p-PERK and its downstream markers, ATF4 and $\mathrm{CHOP}$, were elevated in lung tissue even after 14 days after inhalation injury.

This prolonged elevation of the UPR can be highly detrimental and can lead to ER stress and associated pathology. Our immune-histology data showed that the majority of ATF4 and CHOP staining was contained around the bronchioles. This suggests that collagen deposition around airways seen after inhalation injury in our mice was probably due to a high degree of ER stress in that area. We also found that ATF4 and CHOP levels were elevated in the interalveolar spaces of injured mice, suggesting that ER stress may also be responsible for alveolar septal damage. In fact, the pharmacological inhibition of ER stress by salubrinal or genetic deficiency of ATF4 resulted in reduced airway fibrosis and attenuated alveolar wall destruction and the development of lung emphysematous-like changes in $\mathrm{Br}_{2}$-exposed mice. Previous studies have also shown that ER stress is elevated in the lungs of animals with enlarged alveolar spaces secondary to smoke inhalation (72) or acrolein administration, a toxicant in cigarette smoke (5).

Neutrophil elastase, macrophage elastase, and other elastolytic proteases such as cathepsin G are thought to be the main causative factors of tissue damage in pulmonary emphysema (73). Leukocyte elastase induces epithelial apoptosis $(74,75)$, which contributes to the destruction of lung alveolar septa and the development of emphysema. In our study, we found that plasma elastase levels and BALF elastase 

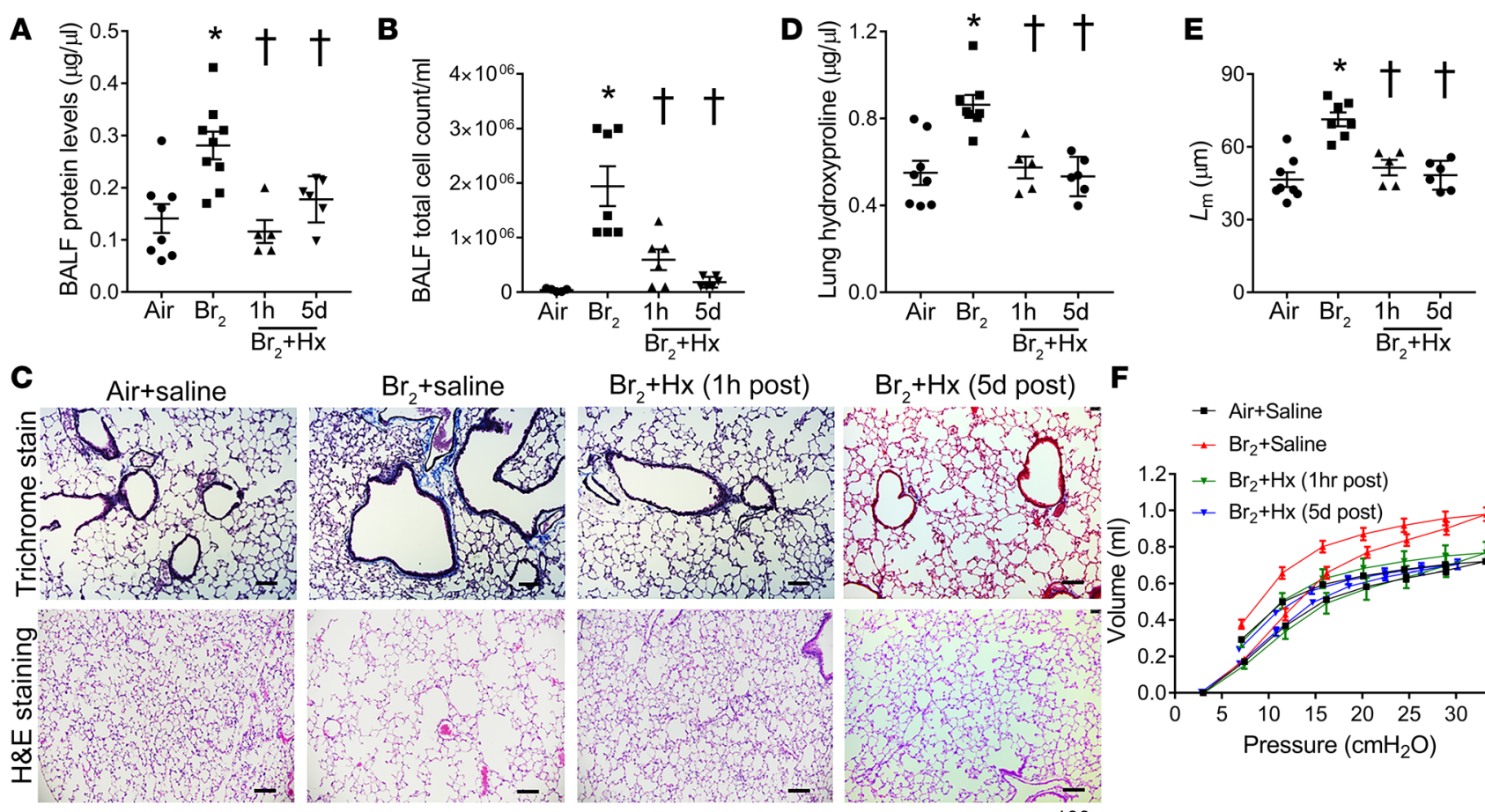

$\mathrm{Br}_{2}+\mathrm{Hx}(1 \mathrm{~h}$ post)

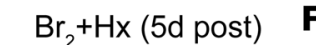

$\mathbf{F}$
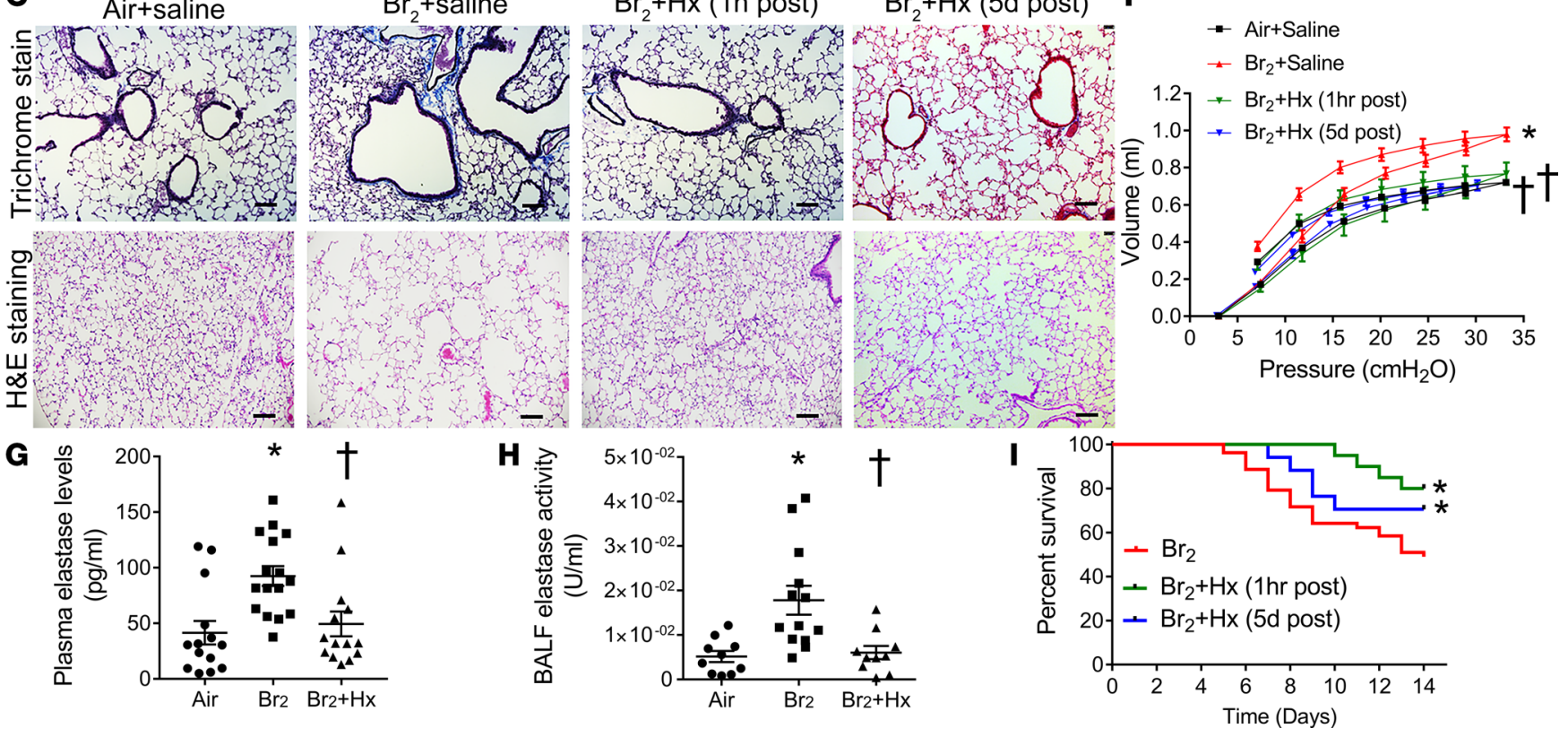

Figure 9. Hemopexin attenuates lung injury, airway fibrosis, and lung emphysema. Male C57BL/6 mice were exposed to air or $\mathrm{Br}_{2}$ gas $(400 \mathrm{ppm}$, 30 minutes) and then returned to room air. Some $\mathrm{Br}_{2}$-exposed mice were given an intraperitoneal injection of purified human hemopexin ( $\mathrm{Hx}$ ) (4 $\mu \mathrm{g} / \mathrm{g} \mathrm{BW}) 1$ hour or 5 days after $\mathrm{Br}_{2}$ exposure. All air-exposed mice and some $\mathrm{Br}_{2}$-exposed mice received saline injection as an appropriate control. Fourteen days after $\mathrm{Br}_{2}$ exposure, mouse BALF protein levels $(n=5-9)(\mathbf{A})$ and total cell count $(n=5-7)(\mathbf{B})$ were elevated in saline-treated mice but were significantly lower in $\mathrm{Hx}$-treated mice. $\mathrm{Hx}$-treated mice had decreased lung deposition of collagen on Masson's trichrome staining ( $n=5$-8) (C) and lower lung hydroxyproline levels $(n=5-8)$ (D) compared with saline-treated mice, 14 days after $\mathrm{Br}_{2}$ inhalation. Assessment of mouse lung pressure-volume $(\mathrm{P}-\mathrm{V})$ curves demonstrated that $\mathrm{Br}_{2}$ exposure increased lung volumes, as indicated by the shifting up and left of $\mathrm{PV}$ curve in the

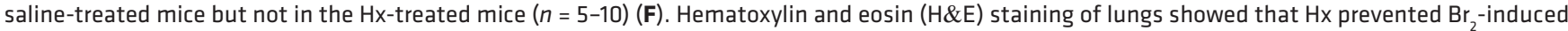
alveolar septa damage $(n=5-8)(\mathbf{C})$ and reduced alveolar $\mathrm{L}_{m}(n=5-8)$. Scale bars $100 \mu \mathrm{m}$. (E). In addition, Hx lowered plasma elastase levels ( $n=$ 14-16) (G) and BALF elastase activity $(n=10-13)(\mathbf{H})$ in $\mathrm{Br}_{2}$-exposed mice. The Kaplan-Meier curve demonstrated that $\mathrm{Hx}$ reduced mortality after $\mathrm{Br}_{2}$ exposure ( $n=42$ for $\mathrm{Br}_{2}+$ saline; $n=20$ for $\mathrm{Br}_{2}+\mathrm{Hx}$ [1 hour after]; $n=17$ for $\mathrm{Br}_{2}+\mathrm{Hx}$ [5 days after]) (I). ${ }^{*} P<0.05$ versus air + saline and ${ }^{\dagger} P<0.05$ versus $\mathrm{Br}_{2}$ + saline by 1-way ANOVA followed by Tukey's post hoc test. PV curves were analyzed by 2-way ANOVA with Bonferroni's post hoc test. Overall survival was analyzed by the Kaplan-Meier method. Differences in survival were tested for statistical significance by the log-rank test.

activity were elevated in mice after inhalation lung injury. Similar increases in elastase activity have been reported after exposure to sulfur mustard (76). Elastase has been shown to induce cellular apoptosis by activating the PERK/CHOP signaling pathway (77). Whether the activation of PERK/CHOP signaling itself influences elastase activity and expression is unknown.

Interestingly, in this study we found that in both salubrinal-treated mice and $\mathrm{ATF} 4^{+/-}$mice, elastase level/activity was attenuated, suggesting that ER stress-mediated regulation of elastase may be responsible for emphysema after inhalation injury. We also found that mice treated with salubrinal had reduced levels of neutrophils and macrophages in their lungs, which may account for the attenuation of elastase level/activity upon ER stress inhibition. Other studies have also shown that abrogation of ER stress reduces inflammatory cells in the lungs (69). In fact, alveolar macrophages themselves are a major source of ER stress (78). Other possible mechanisms of ER stress-mediated regulation of elastase levels/activity may include downregulation of proteinase inhibitor such as $\alpha-1$ antitrypsin, a known inhibitor of neutrophil elastase (79). 
Cellular stress due to reactive species can increase cell apoptosis and ER stress $(41,47,80)$. We have previously shown that nonencapsulated heme is an important source of oxidative stress and is increased in mice after exposure to halogen gas (23). Low blood $\mathrm{pH}$ and elevated levels of halogenated lipids and reactive species after halogen gas exposure can increase the susceptibility of RBCs to hemolysis, resulting in increased heme levels in plasma $(23,81)$. In addition, elevated plasma heme critically affects aging of RBCs via long-term intercalation and destabilization of membranes, resulting in further hemolysis (82). In this study, we found that heme levels were elevated in mice even after 14 days of halogen exposure. We also found that plasma heme levels were higher in patients with very severe COPD and in ferrets exposed to cigarette smoke for 6 months. Interestingly, a previous study also found that cigarette smoke induced hemolysis of rabbit erythrocytes (83).

We also demonstrated that hemin (a form of heme) treatment increased ER stress in HBECs. Therefore, to determine if attenuating heme can be a therapeutic approach to ameliorate chronic lung complications after inhalation injury, we reduced free heme by treating mice with the heme-scavenging protein $\mathrm{Hx}, 1$ hour or 5 days after inhalation injury. Some of the advantages of using Hx over other heme-binding proteins include the following. (a) Unlike desferrioxamine, apotransferrin, and albumin, $\mathrm{Hx}$ can attenuate heme-stimulated lipid peroxidation (84). (b) Unlike albumin and glutathione S-transferases, $\mathrm{Hx}$ is not oxidized by heme, presumably because $\mathrm{H}_{2} \mathrm{O}_{2}$ cannot interact with the bis-histidyl heme- $\mathrm{Hx}$ complex (85). (c) At higher concentrations $(2-10 \mu \mathrm{M})$, the heme-Hx complex increases cell survival (86). In addition, Hx-deficient mice have been shown to have high lipid peroxidation and recover more slowly upon acute hemolysis (87). The administration of $5 \mu \mathrm{M} \mathrm{Hx}$ attenuated free radical production in a rat model of reperfusion injury (88). Similarly, in our study, we found that a single injection of $\mathrm{Hx}$ (4 $\mu \mathrm{g} / \mathrm{g} \mathrm{BW})$ after inhalation injury attenuated plasma heme, reduced lung ER stress, airway fibrosis, emphysema, and also improved survival.

There may be several distinct toxic species that contribute to the development of chronic lung injury. We focused on nonencapsulated cell-free heme because cigarette smoke induces hemolysis (83), and elevated heme/hemoglobin has been shown to mediate lung injury in humans and animals (23, 89-91). In addition, multiple studies including our previous study have shown that scavenging heme by $\mathrm{Hx}$ can ameliorate lung injury $(23,30,90-92)$. Our data demonstrated that the administration of $\mathrm{Hx}(4 \mu \mathrm{g} / \mathrm{g} \mathrm{BW})$ reduced lung inflammation, prevented the development of airway fibrosis and alveolar septal damage, and improved survival in mice exposed to the toxic gas $\mathrm{Br}_{2}$. However, there are several unanswered questions that remain to be verified in future studies. It is surprising that the administration of $4 \mu \mathrm{g} / \mathrm{g} \mathrm{BW}$ of $\mathrm{Hx}$ (total of $100 \mu \mathrm{g}$ in a 25 -g mouse, approximately $1 \mu \mathrm{M}$ concentration and 10 times lower than the endogenous Hx levels in mice) could reduce plasma heme from $50 \mu \mathrm{M}$ to $25 \mu \mathrm{M}$ and prevent chronic lung injury after $\mathrm{Br}_{2}$ exposure. Multiple reasons could explain these effects of Hx. (a) First, it is possible that the endogenous circulating $\mathrm{Hx}$ is already bound to free heme released from basal physiological hemolysis (due to RBC aging) and is not ready to scavenge any de novo acute hemolysis. Therefore, exogenous administration of $\mathrm{Hx}$ has a profound effect in limiting heme levels. (b) Second, elevated plasma heme has been shown to intercalate and destabilize RBC membranes, contributing to ongoing hemolysis and providing a feed-forward mechanism for more heme release (82). Therefore, Hx therapy would not only scavenge free heme but also stabilize RBC membranes, preventing further hemolysis. This could explain why even relatively small amounts of $\mathrm{Hx}$ would be able to reduce high heme levels. (c) Third, our data (Supplemental Figure 5C) suggest that the administration of human Hx stimulates the release of endogenous mouse Hx. The mechanisms contributing to this effect are not clear and need further investigation. (d) Finally, it is entirely possible that the lung-protective effects of Hx may not entirely depend upon heme scavenging and may also involve other antiinflammatory pathways. Past studies have shown that the administration of 1-5 $\mu \mathrm{g} / \mathrm{g}$ BW of $\mathrm{Hx}$ completely abrogated lung

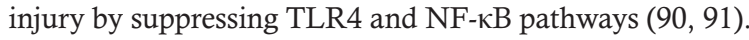

In conclusion, our study has demonstrated that heme-dependent airway damage underlies the pathogenesis of combined lung fibrotic and emphysematous changes after inhalation injury. We have also shown that heme-induced ER stress is a common underlying mechanism involved in chronic lung remodeling. In fact, several environmental inhaled particles such as silica, quartz, and cadmium, known to cause lung fibrosis and emphysema, have potential hemolytic activity (93-95), suggesting that heme could be a potential linker molecule in the combined pathogenesis of lung fibrosis and emphysema. Thus, therapeutic approaches that reduce heme, such as $\mathrm{Hx}$ and to some extent albumin and haptoglobin, in addition to pharmacological inhibition of ER stress may prove to be beneficial countermeasures against inhalation lung injury. 


\section{Methods}

Human subjects. Adult participants were recruited to this observational cohort through the UAB Lung Health Center. Demographic information and smoking history were recorded, pre- and postbronchodilator spirometry was conducted on all participants according to the American Thoracic Society/European Respiratory Society (ATS/ERS) guidelines (96), and phlebotomy was performed. Participants were categorized as COPD based on the ratio of postbronchodilator forced expiratory volume in 1 second to forced vital capacity (FEV1/FVC) less than 0.70 and the severity of airflow limitation (i.e., GOLD 1-4, with GOLD 4 indicating very severe airflow obstruction) (97). Samples were processed, aliquoted, and stored at $-80^{\circ} \mathrm{C}$ using Freezerworks Sample Inventory Management software (Dataworks Development, Inc.). No samples had undergone freeze-thaw cycles prior to use in the study.

Animals. Adult male C57BL/6 mice (20-25 g) were purchased from Charles River, non-Frederick/ NCI. C57BL/ 6 genetic background-based $\mathrm{ATF}^{+/-}$knockout mice were a gift from Marina Gorbatyuk, University of Alabama at Birmingham (UAB), and have a normal appearance and organ morphology. The genotyping of $\mathrm{ATF}^{+/-}$mice was performed using forward primers: ATATTGCTGAAGAGCTTGGCGGC for the Neo allele and AGCAAAACAAGACAGCAGCCACTA for the WT allele and a common reverse primer GTTTCTACAGCTTCCTCCACTCTT for both alleles. All mice were raised under a 12-hour dim light/12-hour dark cycle with access to a standard diet and tap water ad libitum. A euthanasia protocol based on i.p. injections of ketamine and xylazine was used in the study for mice to minimize pain and distress.

Cigarette smoke exposure in ferrets. Outbred WT ferrets (Mustela putorius furo, females [0.6-0.8 kg BW], males [1.2-2.0 kg BW]) were procured from Marshall BioResources. After matching for age and sex, ferrets were randomized to receive whole cigarette smoke exposure or air control groups for 6 months. Following a brief training period, ferrets were acclimatized to customize-designed male and female nose-only exposure tubes and a 36-port plenum connected to smoke output. Ferrets were exposed to two 60-minute sessions of smoke from 3R4F research cigarettes (University of Kentucky) for 5 days/week for 6 months as described previously (14).

Exposure to $\mathrm{Br}_{2}$. Mice were exposed to $\mathrm{Br}_{2}$ gas $(400 \mathrm{ppm})$ in a cylindrical glass chamber for $30 \mathrm{~min}$ utes, as previously described for chlorine gas $(98,99)$. Control mice were exposed to room air in the same experimental conditions as $\mathrm{Br}_{2}$-exposed mice. Exposures were performed with 2 mice in the same chamber at any one time, and all exposures were performed between 6:00 am and 12:00 pm. Tanks were replaced when the pressure in the tanks reached 500 psi. In each case, immediately following exposure, mice were returned to room air.

$H x$ and salubrinal administration. In some experiments starting at 1 hour after $\mathrm{Br}_{2}$ exposure, mice were treated daily with either salubrinal (SML0951; Sigma-Aldrich), an ER stress inhibitor, dissolved in DMSO or control vehicle (DMSO) for 13 consecutive days at the dose of $1 \mathrm{mg} / \mathrm{kg}$ BW by i.p. injection. In other experiments, mice were treated with a single i.p. injection of Hx (product no. 16-16-080513-LEL; Athens Research and Technology) dissolved in normal saline at the dose of $4 \mu \mathrm{g} / \mathrm{g} \mathrm{BW}$, either 1 hour or 5 days after $\mathrm{Br}_{2}$ exposure and mice were sacrificed and used for experiments on the 14th day after exposure.

Assessment of respiratory mechanics. PV curves with constant increasing pressure (PVr-P) were assessed in mice anesthetized with pentobarbital (50 mg/kg i.p.; Vortech Pharmaceuticals), paralyzed with pancuronium (4 mg/kg i.p.; Gensia Sicor Pharmaceuticals), intubated, connected to an FX-1 module of the FlexiVent (SCIREQ), and ventilated at a rate of 160 breaths per minute at a tidal volume of $0.2 \mathrm{ml}$ with a positive endexpiratory pressure of $3 \mathrm{cmH}_{2} \mathrm{O}$. Each time before performing PV-loop perturbations, a total lung capacity perturbation (TLC) was carried out to normalize the lungs. PVr-P perturbations were performed until 3 acceptable measurements (coefficient of determination [COD] > 0.95) were recorded in each subject, of which an average was calculated. Raw data from the PVr-P perturbation were used to reconstruct PV curves. Lung compliance $(\mathrm{C}, \Delta \mathrm{V} / \Delta \mathrm{P})$ was derived from the PV curves on the deflation (upper) limb between lung pressures of 7 and $11.4 \mathrm{cmH}_{2} \mathrm{O}$ as described previously (100). When measured under closed-chest conditions, this variable reflects the intrinsic elastic properties of the respiratory system (i.e., lung + chest wall) at rest. Estimate of inspiratory capacity is the upper bounds estimate of the difference between total lung capacity and zero volume.

Histological analysis and Masson's trichrome staining of mouse lung. Lung tissues were removed and fixed in $70 \%$ alcoholic formalin for 24 hours and dehydrated in $70 \%$ ethanol before embedding in paraffin. Paraffin-embedded tissues were cut into 4 - $\mu \mathrm{m}$ sections, deparaffinized, and rehydrated using CitriSolv (d-limonene-based solvent) and isopropanol, respectively. The sections were stained for ATF4 (11815S, Cell 
Signaling Technology), CHOP (2895, Cell Signaling Technology), with H\&E, or with Masson's trichrome (71). H\&E-stained sections were used to assess $\mathrm{L}_{\mathrm{m}}$, which is widely accepted as an indicator of the presence of emphysema. $\mathrm{L}_{\mathrm{m}}$ was measured by dividing the total length of lines drawn across the 20 randomly selected lung fields by number of intercepts with alveolar septum at $\times 200$ magnification. Alveoli number was determined by the number of measurements made for the $\mathrm{L}_{\mathrm{m}}$. Trichrome-stained lung section images were captured using a Leica DMI 6000 B microscope.

$B A L F$ analysis. Mice were euthanized with an i.p. injection of ketamine and xylazine (100 and 10 $\mathrm{mg} / \mathrm{kg}$ body weight, respectively). The lungs were lavaged, and the recovered lavage fluid was centrifuged immediately at 3,000 $\mathrm{g}$ for 10 minutes to pellet the cells. Supernatants were used for protein analysis using the Pierce BCA Protein Assay (product no. 23225; Thermo Scientific, Rockford, IL). Pelleted cells were counted using a Neubauer hemocytometer and then stained using a 2-stain set consisting of eosin Y and a solution of thiazine dyes for differential counts (23).

Plasma heme assay. Heme levels were measured in plasma samples using the QuantiChrom heme assay kit (product no. DIHM-250; BioAssay Systems), according to the manufacturer's instructions.

Plasma Hx measurement. Plasma levels of endogenous mouse $\mathrm{Hx}$ levels were measured in mice using an ELISA kit (product no. GWB-D5D320; GenWay Biotech, Inc.) according to the manufacturer's instructions. Similarly, plasma levels of human $\mathrm{Hx}$ were measured in mice after injection of purified human $\mathrm{Hx}$ using an ELISA kit (product no. GWB-4B6D1A [40-374-130039]; GenWay Biotech, Inc.) according to the manufacturer's instructions.

Hydroxyproline quantification. Hydroxyproline level was measured by using a hydroxyproline assay kit (MAK008, Sigma-Aldrich). Briefly, $20 \mathrm{mg}$ of whole lung tissue disrupted in liquid nitrogen was hydrolyzed for 3 hours in $12 \mathrm{~N} \mathrm{HCl}$ at $120^{\circ} \mathrm{C}$. After cooling down for 20 minutes, $30 \mu 1$ from each sample was transferred to a 96 -well plate and evaporated at $60^{\circ} \mathrm{C}$ overnight. Hydroxyproline level was measured in these samples according to the manufacturer's instructions.

Measurement of elastase levels and activity. Neutrophil elastase levels in plasma samples were measured by using a standard kit (DY4517-05, Mouse Neutrophil Elastase DuoSet ELISA, R\&D Systems). Elastase activity was measured in the BALF samples by using an EnzChek Elastase Assay kit (E12056, Molecular Probes). One unit of elastase activity is defined as the amount of enzyme required to solubilize $1 \mathrm{mg}$ of elastin in 20 minutes at $\mathrm{pH} 8.8$ and $37^{\circ} \mathrm{C}$. BALF total elastase levels could not be detected due to low sensitivity of the assay.

Assessment of ER stress. ER stress was analyzed by measuring Grp78 using a Grp78/Bip ELISA kit (ADI900-214, Enzo Life Sciences) according to the manufacturer's instructions. Immunoblot was performed using primary antibodies at 1:1,000 dilution against CHOP (2895S), ATF4 (11815S), total IRE1 $\alpha$ (3294S), p-PERK (3179S), p-eIF2 $\alpha$ (9721S), total eIF2 $\alpha$ (9722S) (all Cell Signalling Technology); ATF6 (sc22799), total PERK (sc13073), Grp78 (sc13968) (all Santa Cruz Biotechnology); and p-IRE1 $\alpha$ (NB100-2323, Novus Biologicals) as described previously (23). Bands were detected by a chemiluminescent HRP substrate (Millipore). Protein loading was normalized by reprobing the membranes with an antibody specific for $\beta$-actin (Sigma-Aldrich).

Cell culture. HBECs were a gift from Kevin Harrod at UAB and were maintained in Bronchial Epithelial Cell Basal Medium (Lonza). Immediately before exposure to hemin or $\mathrm{Br}_{2}$, culture media were replaced with phenol red-free culture media. For $\mathrm{Br}_{2}$ exposure, cells were placed in a glass chamber inside a water-jacketed incubator maintained at $37^{\circ} \mathrm{C}$ and exposed to $100 \mathrm{ppm} \mathrm{Br}_{2}$ for 10 minutes. The concentration of $\mathrm{Br}_{2}$ in the chamber was measured continuously with an Interscan Corp. (model RM70$20.0 \mathrm{~m}) \mathrm{Br}_{2}$ detector. After exposure, cells were placed in a humidified incubator with air and $5 \% \mathrm{CO}_{2}$ at $37^{\circ} \mathrm{C}$ for 6 or 24 hours.

Statistics. Statistical analysis was performed using GraphPad Prism version 7 for Windows. The mean \pm SEM was calculated in all experiments, and statistical significance was determined by unpaired $t$ test for 2 groups or 1-way ANOVA followed by Tukey's post hoc testing for more than 2 groups. PV curves were analyzed by 2-way ANOVA and Bonferroni's post hoc test. Overall survival was analyzed by the Kaplan-Meier method. Differences in survival were tested for statistical significance by the log-rank test. $P$ less than 0.05 was considered significant.

Study approval. Adult participants were recruited to this observational cohort through the UAB Lung Health Center. The study was approved by the UAB Institutional Review Board (Birmingham, AL; IRB Protocol X170301002). All animal care and experimental procedures were approved by the Institutional Animal Care and Use Committee at the UAB (Animal Protocol number: 20761). 


\section{Author contributions}

SA designed the study, acquired, analyzed, and interpreted data, and wrote the manuscript. IA acquired, analyzed, and interpreted data. AL, MAC, and CL acquired and analyzed data. MJW and JMW acquired human samples. SVR acquired ferret samples. MA designed the study, analyzed and interpreted data, and was responsible for quality control. SM designed the study, analyzed and interpreted data, wrote the manuscript, and was responsible for quality control. SMR and SVR acquired ferret samples.

\section{Acknowledgments}

The authors would like to thank Zhihong Yu, Stephen F. Doran, Nilam Vital, Amie, Traylor, and Jeannette Eagen for their technical support in the generation of the manuscript. HBECs were provided by Kevin Harrod from UAB. This work was supported by the CounterACT Program, NIH Office of the Director, the National Institute of Neurological Disorders and Stroke (NINDS), and the National Institute of Environmental Health Sciences (NIEHS), grant numbers 5 UO1 ES026458 03, 3UO1 ES026458 03S1, and 5UO1 ES027697 02 (to SM); and by the NIH National Heart, Lung, and Blood Institute grant K08 HL123940 (to JMW). National Institute of Environmental Health Sciences, grant number 5R01ES026219-03 (to MA).

Address correspondence to: Sadis Matalon, BMR II 224, 901 19th Street South, Birmingham, Alabama 35205-3703, USA. Phone: 205.975.7476; Email: smatalon@uabmc.edu.

1. Auerbach O, Garfinkel L, Hammond EC. Relation of smoking and age to findings in lung parenchyma: a microscopic study. Chest. 1974;65(1):29-35.

2. Cottin V, et al. Pulmonary hypertension in patients with combined pulmonary fibrosis and emphysema syndrome. Eur Respir J. 2010;35(1):105-111.

3. Cottin V, et al. Combined pulmonary fibrosis and emphysema: a distinct underrecognised entity. Eur Respir J. 2005;26(4):586-593.

4. Grubstein A, Bendayan D, Schactman I, Cohen M, Shitrit D, Kramer MR. Concomitant upper-lobe bullous emphysema, lower-lobe interstitial fibrosis and pulmonary hypertension in heavy smokers: report of eight cases and review of the literature. Respir Med. 2005;99(8):948-954.

5. Kitaguchi Y, Fujimoto K, Hanaoka M, Kawakami S, Honda T, Kubo K. Clinical characteristics of combined pulmonary fibrosis and emphysema. Respirology. 2010;15(2):265-271.

6. Kitaguchi Y, Fujimoto K, Hayashi R, Hanaoka M, Honda T, Kubo K. Annual changes in pulmonary function in combined pulmonary fibrosis and emphysema: over a 5-year follow-up. Respir Med. 2013;107(12):1986-1992.

7. Wiggins J, Strickland B, Turner-Warwick M. Combined cryptogenic fibrosing alveolitis and emphysema: the value of high resolution computed tomography in assessment. Respir Med. 1990;84(5):365-369.

8. Hoesein FAM, Voortman M, Kwakkel-van Erp JM, Luijk B, de Jong PA. Images in COPD: combined pulmonary emphysema and fibrosis with pulmonary hypertension. Chronic Obstr Pulm Dis. 2017;4(1):76-80.

9. Daniil Z, Koutsokera A, Gourgoulianis K. Combined pulmonary fibrosis and emphysema in patients exposed to agrochemical compounds. Eur Respir J. 2006;27(2):434

10. Karkhanis VS, Joshi JM. Combined pulmonary fibrosis and emphysema in a tyre industry worker. Lung India. 2012;29(3):273-276.

11. Bartalesi B, et al. Different lung responses to cigarette smoke in two strains of mice sensitive to oxidants. Eur Respir J. 2005;25(1):15-22.

12. Matalon S. A critical review of the American Journal of Physiology-Lung Cellular and Molecular Physiology: 2012-2015. Am J Physiol Lung Cell Mol Physiol. 2014;307(12):L911-L916.

13. Zhang Y, Li Y, Shi C, Fu X, Zhao L, Song Y. Angiotensin-(1-7)-mediated Mas1 receptor/NF-кB-p65 signaling is involved in a cigarette smoke-induced chronic obstructive pulmonary disease mouse model. Environ Toxicol. 2018;33(1):5-15.

14. Raju SV, et al. A ferret model of COPD-related chronic bronchitis. JCI Insight. 2016;1(15):e87536.

15. Yun JH, et al. Transcriptomic analysis of lung tissue from cigarette smoke-induced emphysema murine models and human chronic obstructive pulmonary disease show shared and distinct pathways. Am J Respir Cell Mol Biol. 2017;57(1):47-58.

16. Mori H, et al. Phosphodiesterase 4 inhibitor GPD-1116 markedly attenuates the development of cigarette smoke-induced emphysema in senescence-accelerated mice P1 strain. Am J Physiol Lung Cell Mol Physiol. 2008;294(2):L196-L204.

17. Woolf A, Shannon M. Reactive airways dysfunction and systemic complaints after mass exposure to bromine. Environ Health Perspect. 1999;107(6):507-509.

18. Inagaki N, et al. Case with bromine exposure leading to respiratory insufficiency. Chudoku Kenkyu. 2005;18(2):141-147.

19. Kraut A, Lilis R. Chemical pneumonitis due to exposure to bromine compounds. Chest. 1988;94(1):208-210.

20. Lossos IS, Abolnik I, Breuer R. Pneumomediastinum: a complication of exposure to bromine. Br J Ind Med. 1990;47(11):784.

21. Häsänen E, Manninen PKG, Himberg K. Chlorine and bromine contents in tobacco and tobacco smoke. J Radioanal Nucl Chem. 1990;144(5):367-374

22. Duerr MA, et al. Bromofatty aldehyde derived from bromine exposure and myeloperoxidase and eosinophil peroxidase modify GSH and protein. J Lipid Res. 2018;59(4):696-705.

23. Aggarwal S, et al. Heme attenuation ameliorates irritant gas inhalation-induced acute lung injury. Antioxid Redox Signal. 2016;24(2):99-112.

24. Rojas D, et al. Osmotic fragility of red blood cells, lipid peroxidation and $\mathrm{Ca}^{2+}$-ATPase activity of placental homogenates and red blood cell ghosts in salt-loaded pregnant rats. J Matern Fetal Neonatal Med. 2016;29(2):229-233. 
25. Nagy E, et al. Red cells, hemoglobin, heme, iron, and atherogenesis. Arterioscler Thromb Vasc Biol. 2010;30(7):1347-1353.

26. Li L, Frei B. Prolonged exposure to LPS increases iron, heme, and p22phox levels and NADPH oxidase activity in human aortic endothelial cells: inhibition by desferrioxamine. Arterioscler Thromb Vasc Biol. 2009;29(5):732-738.

27. Shannahan JH, et al. The role of iron in Libby amphibole-induced acute lung injury and inflammation. Inhal Toxicol. 2011;23(6):313-323.

28. Dennery PA, et al. Resistance to hyperoxia with heme oxygenase-1 disruption: role of iron. Free Radic Biol Med. 2003;34(1):124-133.

29. Kato GJ, Steinberg MH, Gladwin MT. Intravascular hemolysis and the pathophysiology of sickle cell disease. J Clin Invest. 2017;127(3):750-760.

30. Stapley R, et al. Red blood cell washing, nitrite therapy, and antiheme therapies prevent stored red blood cell toxicity after trauma-hemorrhage. Free Radic Biol Med. 2015;85:207-218.

31. Higdon AN, et al. Hemin causes mitochondrial dysfunction in endothelial cells through promoting lipid peroxidation: the protective role of autophagy. Am J Physiol Heart Circ Physiol. 2012;302(7):H1394-H1409.

32. Supinski GS, Alimov AP, Wang L, Song XH, Callahan LA. Calcium-dependent phospholipase A2 modulates infection-induced diaphragm dysfunction. Am J Physiol Lung Cell Mol Physiol. 2016;310(10):L975-L984.

33. Fortes GB, et al. Heme induces programmed necrosis on macrophages through autocrine TNF and ROS production. Blood. 2012;119(10):2368-2375.

34. Thomas DD, Espey MG, Vitek MP, Miranda KM, Wink DA. Protein nitration is mediated by heme and free metals through

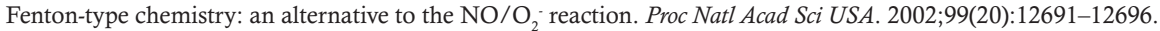

35. Balla J, et al. Heme, heme oxygenase, and ferritin: how the vascular endothelium survives (and dies) in an iron-rich environment. Antioxid Redox Signal. 2007;9(12):2119-2137.

36. Heide K, Haupt H, Stoeriko K, Schultze He. On the heme-binding capacity of hemopexin. Clin Chim Acta. 1964;10:460-469.

37. Killander J. Separation of human heme- and hemoglobin-binding plasma proteins, ceruloplasmin and albumin by gel filtration. Biochim Biophys Acta. 1964;93:1-14.

38. Miller YI, Smith A, Morgan WT, Shaklai N. Role of hemopexin in protection of low-density lipoprotein against hemoglobin-induced oxidation. Biochemistry. 1996;35(40):13112-13117.

39. Nagel RL, Gibson QH. The binding of hemoglobin to haptoglobin and its relation to subunit dissociation of hemoglobin. J Biol Chem. 1971;246(1):69-73.

40. Hvidberg V, Maniecki MB, Jacobsen C, Højrup P, Møller HJ, Moestrup SK. Identification of the receptor scavenging hemopexin-heme complexes. Blood. 2005;106(7):2572-2579.

41. Yu SN, et al. Salinomycin induces endoplasmic reticulum stress-mediated autophagy and apoptosis through generation of reactive oxygen species in human glioma U87MG cells. Oncol Rep. 2017;37(6):3321-3328.

42. Ayaub EA, et al. GRP78 and CHOP modulate macrophage apoptosis and the development of bleomycin-induced pulmonary fibrosis. J Pathol. 2016;239(4):411-425

43. Kitaguchi Y, Taraseviciene-Stewart L, Hanaoka M, Natarajan R, Kraskauskas D, Voelkel NF. Acrolein induces endoplasmic reticulum stress and causes airspace enlargement. PLoS One. 2012;7(5):e38038.

44. Lin T, et al. Hemopexin in severe inflammation and infection: mouse models and human diseases. Crit Care. 2015;19:166.

45. Vogelmeier CF, et al. Global Strategy for the Diagnosis, Management, and Prevention of Chronic Obstructive Lung Disease 2017 Report: GOLD Executive Summary. Arch Bronconeumol. 2017;53(3):128-149.

46. Zhang L, et al. Endoplasmic reticulum stress, a new wrestler, in the pathogenesis of idiopathic pulmonary fibrosis. Am J Transl Res. 2017;9(2):722-735.

47. Baek HA, et al. Involvement of endoplasmic reticulum stress in myofibroblastic differentiation of lung fibroblasts. Am J Respir Cell Mol Biol. 2012;46(6):731-739.

48. Wang M, Wey S, Zhang Y, Ye R, Lee AS. Role of the unfolded protein response regulator GRP78/BiP in development, cancer, and neurological disorders. Antioxid Redox Signal. 2009;11(9):2307-2316

49. Sharafkhaneh A, Hanania NA, Kim V. Pathogenesis of emphysema: from the bench to the bedside. Proc Am Thorac Soc. 2008;5(4):475-477.

50. Boyce M, et al. A selective inhibitor of eIF2alpha dephosphorylation protects cells from ER stress. Science. 2005;307(5711):935-939.

51. Moreno JA, et al. Sustained translational repression by eIF2 $\alpha$-P mediates prion neurodegeneration. Nature. 2012;485(7399):507-511.

52. Liu CL, et al. Salubrinal protects against tunicamycin and hypoxia induced cardiomyocyte apoptosis via the PERK-eIF2 $\alpha$ signaling pathway. J Geriatr Cardiol. 2012;9(3):258-268.

53. Lambert JA, et al. Mechanisms and treatment of halogen inhalation-induced pulmonary and systemic injuries in pregnant mice. Hypertension. 2017;70(2):390-400.

54. Ford DA, et al. Formation of chlorinated lipids post-chlorine gas exposure. J Lipid Res. 2016;57(8):1529-1540

55. Zaky A, et al. Chlorine inhalation-induced myocardial depression and failure. Physiol Rep. 2015;3(6):e12439.

56. Carlisle M, Lam A, Svendsen ER, Aggarwal S, Matalon S. Chlorine-induced cardiopulmonary injury. Ann N Y Acad Sci. 2016;1374(1):159-167.

57. Honavar J, Doran S, Oh JY, Steele C, Matalon S, Patel RP. Nitrite therapy improves survival postexposure to chlorine gas. Am J Physiol Lung Cell Mol Physiol. 2014;307(11):L888-L894.

58. Honavar J, Doran S, Ricart K, Matalon S, Patel RP. Nitrite therapy prevents chlorine gas toxicity in rabbits. Toxicol Lett. 2017;271:20-25

59. Musah S, Schlueter CF, Humphrey DM, Powell KS, Roberts AM, Hoyle GW. Acute lung injury and persistent small airway disease in a rabbit model of chlorine inhalation. Toxicol Appl Pharmacol. 2017;315:1-11.

60. Hoyle GW, Svendsen ER. Persistent effects of chlorine inhalation on respiratory health. Ann N Y Acad Sci. 2016;1378(1):33-40.

61. Todd NW, et al. Centrilobular emphysema combined with pulmonary fibrosis results in improved survival. Fibrogenesis Tissue Repair. 2011;4(1):6.

62. Akagi T, et al. Coexistent emphysema delays the decrease of vital capacity in idiopathic pulmonary fibrosis. Respir Med. 
2009;103(8):1209-1215.

63. Mejía M, et al. Idiopathic pulmonary fibrosis and emphysema: decreased survival associated with severe pulmonary arterial hypertension. Chest. 2009;136(1):10-15.

64. Kim YJ, et al. Annual change in pulmonary function and clinical characteristics of combined pulmonary fibrosis and emphysema and idiopathic pulmonary fibrosis: Over a 3-year follow-up. Tuberc Respir Dis (Seoul). 2014;77(1):18-23.

65. Chiang CK, et al. Endoplasmic reticulum stress implicated in the development of renal fibrosis. Mol Med. 2011;17(11-12):1295-1305.

66. Ayala P, et al. Attenuation of endoplasmic reticulum stress using the chemical chaperone 4-phenylbutyric acid prevents cardiac fibrosis induced by isoproterenol. Exp Mol Pathol. 2012;92(1):97-104.

67. Tamaki N, et al. CHOP deficiency attenuates cholestasis-induced liver fibrosis by reduction of hepatocyte injury. Am J Physiol Gastrointest Liver Physiol. 2008;294(2):G498-G505.

68. Lawson WE, et al. Endoplasmic reticulum stress enhances fibrotic remodeling in the lungs. Proc Natl Acad Sci U S A. 2011;108(26):10562-10567.

69. Yao Y, et al. Chop deficiency protects mice against bleomycin-induced pulmonary fibrosis by attenuating M2 macrophage production. Mol Ther. 2016;24(5):915-925

70. Tanaka Y, et al. The exacerbating roles of CCAAT/enhancer-binding protein homologous protein (CHOP) in the development of bleomycin-induced pulmonary fibrosis and the preventive effects of tauroursodeoxycholic acid (TUDCA) against pulmonary fibrosis in mice. Pharmacol Res. 2015;99:52-62.

71. Li C, et al. Chlorine induces the unfolded protein response in murine lungs and skin. Am J Respir Cell Mol Biol. 2013;49(2):197-203.

72. Gan G, et al. The role of endoplasmic reticulum stress in emphysema results from cigarette smoke exposure. Cell Physiol Biochem. 2011;28(4):725-732.

73. Lucey EC, Keane J, Kuang PP, Snider GL, Goldstein RH. Severity of elastase-induced emphysema is decreased in tumor necrosis factor-alpha and interleukin-1beta receptor-deficient mice. Lab Invest. 2002;82(1):79-85.

74. Ginzberg HH, et al. Leukocyte elastase induces epithelial apoptosis: role of mitochondial permeability changes and Akt. Am J Physiol Gastrointest Liver Physiol. 2004;287(1):G286-G298.

75. Hou HH, Cheng SL, Liu HT, Yang FZ, Wang HC, Yu CJ. Elastase induced lung epithelial cell apoptosis and emphysema through placenta growth factor. Cell Death Dis. 2013;4:e793.

76. Shahriary A, Mehrani H, Ghanei M, Parvin S. Comparative proteome analysis of peripheral neutrophils from sulfur mustard-exposed and COPD patients. J Immunotoxicol. 2015;12(2):132-139.

77. Grechowa I, Horke S, Wallrath A, Vahl CF, Dorweiler B. Human neutrophil elastase induces endothelial cell apoptosis by activating the PERK-CHOP branch of the unfolded protein response. FASEB J. 2017;31(9):3868-3881.

78. Ryan AJ, Larson-Casey JL, He C, Murthy S, Carter AB. Asbestos-induced disruption of calcium homeostasis induces endoplasmic reticulum stress in macrophages. J Biol Chem. 2014;289(48):33391-33403.

79. Krotova K, et al. $\alpha-1$ Antitrypsin-deficient macrophages have increased matriptase-mediated proteolytic activity. Am J Respir Cell Mol Biol. 2017;57(2):238-247.

80. Yuzefovych LV, LeDoux SP, Wilson GL, Rachek LI. Mitochondrial DNA damage via augmented oxidative stress regulates endoplasmic reticulum stress and autophagy: crosstalk, links and signaling. PLoS ONE. 2013;8(12):e83349.

81. Perrone S, Tataranno ML, Stazzoni G, Del Vecchio A, Buonocore G. Oxidative injury in neonatal erythrocytes. J Matern Fetal Neonatal Med. 2012;25(suppl 5):104-108.

82. Solar I, Muller-Eberhard U, Shviro Y, Shaklai N. Long-term intercalation of residual hemin in erythrocyte membranes distorts the cell. Biochim Biophys Acta. 1991;1062(1):51-58.

83. Minamisawa S, Komuro E, Niki E. Hemolysis of rabbit erythrocytes induced by cigarette smoke. Life Sci. 1990;47(24):2207-2215

84. Gutteridge JM, Smith A. Antioxidant protection by haemopexin of haem-stimulated lipid peroxidation. Biochem J. 1988;256(3):861-865.

85. Vincent SH, Grady RW, Shaklai N, Snider JM, Muller-Eberhard U. The influence of heme-binding proteins in heme-catalyzed oxidations. Arch Biochem Biophys. 1988;265(2):539-550.

86. Eskew JD, Vanacore RM, Sung L, Morales PJ, Smith A. Cellular protection mechanisms against extracellular heme. heme-hemopexin, but not free heme, activates the N-terminal c-jun kinase. J Biol Chem. 1999;274(2):638-648.

87. Tolosano E, et al. Defective recovery and severe renal damage after acute hemolysis in hemopexin-deficient mice. Blood. 1999;94(11):3906-3914.

88. Brass CA, Immenschuh S, Song DX, Liem HH, Eberhard UM. Hemopexin decreases spontaneous chemiluminescence of cold preserved liver after reperfusion. Biochem Biophys Res Commun. 1998;248(3):574-577.

89. Shaver CM, et al. Cell-free hemoglobin: a novel mediator of acute lung injury. Am J Physiol Lung Cell Mol Physiol. 2016;310(6):L532-L541.

90. Wagener BM, et al. Role of heme in lung bacterial infection after trauma hemorrhage and stored red blood cell transfusion: A preclinical experimental study. PLoS Med. 2018;15(3):e1002522.

91. Jung JY, Kwak YH, Chang I, Kwon WY, Suh GJ, Choi D. Protective effect of hemopexin on systemic inflammation and acute lung injury in an endotoxemia model. J Surg Res. 2017;212:15-21.

92. Graw JA, et al. Haptoglobin or hemopexin therapy prevents acute adverse effects of resuscitation after prolonged storage of red cells. Circulation. 2016;134(13):945-960.

93. Pavan C, Rabolli V, Tomatis M, Fubini B, Lison D. Why does the hemolytic activity of silica predict its pro-inflammatory activity? Part Fibre Toxicol. 2014;11:76.

94. Wiessner JH, Mandel NS, Sohnle PG, Mandel GS. Effect of particle size on quartz-induced hemolysis and on lung inflammation and fibrosis. Exp Lung Res. 1989;15(6):801-812.

95. Horiguchi H, Oguma E, Kayama F. Cadmium induces anemia through interdependent progress of hemolysis, body iron accumulation, and insufficient erythropoietin production in rats. Toxicol Sci. 2011;122(1):198-210.

96. Miller MR, et al. Standardisation of spirometry. Eur Respir J. 2005;26(2):319-338.

97. Vogelmeier CF, et al. Global Strategy for the Diagnosis, Management, and Prevention of Chronic Obstructive Lung Disease 2017 Report. GOLD Executive Summary. Am J Respir Crit Care Med. 2017;195(5):557-582. 
98. Leustik M, et al. Mitigation of chlorine-induced lung injury by low-molecular-weight antioxidants. Am J Physiol Lung Cell Mol Physiol. 2008;295(5):L733-L743.

99. Song W, et al. Inhibition of lung fluid clearance and epithelial $\mathrm{Na}^{+}$channels by chlorine, hypochlorous acid, and chloramines. J Biol Chem. 2010;285(13):9716-9728.

100. Vardell E. JoVE: the Journal of Visualized Experiments. Med Ref Serv Q. 2015;34(1):88-97. 